PATRICIA ROTTA LOPES

Avaliação da progesterona salivar em cadelas durante o período peri-ovulatório

São Paulo

2012 


\section{Avaliação da progesterona salivar em cadelas durante o período peri-ovulatório}

Dissertação apresentada ao Programa de PósGraduação em Reprodução Animal da Faculdade de Medicina Veterinária e Zootecnia da Universidade de São Paulo para obtenção do título de Mestre em Ciências

Departamento:

Reprodução Animal

Área de concentração:

Reprodução Animal

Orientador:

Prof. Dr. Cláudio Alvarenga de Oliveira

São Paulo

2012 
Autorizo a reprodução parcial ou total desta obra, para fins acadêmicos, desde que citada a fonte.

\section{DADOS INTERNACIONAIS DE CATALOGAÇÃO-NA-PUBLICAÇÃO}

(Biblioteca Virginie Buff D'Ápice da Faculdade de Medicina Veterinária e Zootecnia da Universidade de São Paulo)

Lopes, Patricia Rotta

FMVZ

Avaliação da progesterona salivar em cadelas durante o período periovulatório / Patricia Rotta Lopes. -- 2012. $65 \mathrm{f}$.

Dissertação (Mestrado) - Universidade de São Paulo. Faculdade de Medicina Veterinária e Zootecnia. Departamento de Reprodução Animal, São Paulo, 2012.

Programa de Pós-Graduação: Reprodução Animal.

Área de concentração: Reprodução Animal.

Orientador: Prof. Dr. Cláudio Alvarenga de Oliveira.

1. Imunoensaio. 2. Progesterona. 3. Saliva. 4. Cadelas. 5. Reprodução. I. Título. 


\section{UNIVERSIDADE DE SÃo PAULO}

\section{FACULDADE DE MEDICINA VETERIVÁRIA E ZOOTECNIA}

\section{CERTIFICADO}

Certificamos que o Projeto intitulado "Avaliaçāo da progesterona salivar comparativamente à progesterona plasmática em cadelas durante o ciclo estral visando a reproduçăo assistida", protocolado sob o n'1754/2009, utilizando 15 (quinze) cachorros pretos, sob a responsabilidade do Prof. Dr. Cláudio Alvarenga de Oliveira, está de acordo com os principios éticos de experimentação animal da Comissão de Bioética da Faculdade de Medicina Veterinária e Zootecnia da Universidade de Sầ Paulo e foi aprovado em reuniâo de 09 de setembro de 2009.

We certify that the Research "Evaluation of salivary progesterone compared to plasmatic progesterone in bitches during the estrous cycle aiming assisted reproduction", utilizing 15 (fifteen) dogs, protocol number $1754 / 2009$, under the responsibility Prof. Dr. Claudio Alvarenga de Oliveira, agree with Ethical Principles in Animal Research adopted by Bioethic Commission of the School of Veterinary Medicine and Animal Science of University of Săo Paulo and was approved in the meeting of day 09/09/09.

São Paulo, 10 de setembro de 2009

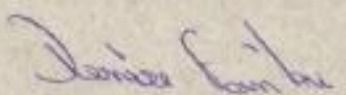

Profa Dra Denise Tabacchi Fantoni

Presidente da Comissāo de Bioética FMVZ/USP 


\section{FOLHA DE AVALIAÇÃO}

Nome: LOPES, Patricia Rotta

Título: Avaliação da progesterona salivar em cadelas durante o período periovulatório

Dissertação apresentada ao Programa de PósGraduação em Reprodução Animal da Faculdade de Medicina Veterinária e Zootecnia da Universidade de São Paulo para obtenção do título de Mestre em Ciências

Data:

Banca Examinadora

Prof.Dr.

Instituição Julgamento

Prof.Dr.

Instituição Julgamento

Prof.Dr. Instituição Julgamento 
Aos animais

...razão do meu trabalho!

\author{
Dedico
}




\section{AGRADECIMENTOS}

Ao meu orientador Prof. Dr. Claudio Alvarenga de Oliveira, pela confiança depositada em mim, por ter me aceitado como sua orientada, por ter me dado a oportunidade de realizar esse sonho.

À Dra. Priscila Viau Furtado, por todo carinho, amizade, ajuda, paciência, colaboração e muito mais.

Ao Médico Veterinário José Sérgio de Arruda Gonçalves, por ter me aberto as portas de seu canil.

À Médica Veterinária Fernanda Regazzi, pela grande colaboração.

À amiga e colega de laboratório Lilian Mara Kirsch Dias.

Ao Departamento de Reprodução Animal por ter me acolhido e a todos que dele fazem parte. Aos professores, pelos ensinamentos nas disciplinas. Aos colegas de disciplinas e do LDH.

A todas as cadelas que participaram do experimento, que "quase sem reclamar", gentilmente permitiram que eu coletasse um pouquinho de seus fluidos biológicos.

À FAPESP, pela bolsa e auxílio concedidos.

E a todos que não mencionei e que colaboraram, de forma direta ou indireta, agradeço imensamente. 
"Todo conhecimento é vão, salvo quando há trabalho.

Todo trabalho é vazio, salvo quando há amor."

(Kahlil Gibran) 


\section{RESUMO}

LOPES, P. R. Avaliação da progesterona salivar em cadelas durante o período peri-ovulatório. [Evaluation of salivary progesterone in bitches during periovulatory period]. 2012. 65 f. Dissertação (Mestrado em Ciências) - Faculdade de Medicina Veterinária e Zootecnia, Universidade de São Paulo, São Paulo, 2012.

Vários autores já enfatizaram a importância do monitoramento do ciclo estral em cadelas e citaram exemplos de como ele pode ser feito. $\mathrm{O}$ objetivo deste estudo foi avaliar a técnica de dosagem de progesterona salivar para monitorar o ciclo estral da espécie. Para composição do grupo experimental, foram utilizadas 13 cadelas. As amostras de sangue e saliva foram colhidas paralelamente em todos os animais, a partir dos primeiros sinais de proestro. As amostras salivares foram obtidas com o uso de dispositivo específico para coleta Salivette ${ }^{\circledR}$, método que se mostrou eficaz, visto que foi possível obter volume suficiente para dosagem de progesterona na grande maioria das amostras. As concentrações de progesterona no soro foram determinadas pela técnica de RIE e na saliva por EIE. Embora haja uma relação linear crescente e positiva entre a progesterona sérica e salivar $(r=0,704 ; p<0,0001)$, não é possível utilizar o parâmetro salivar para determinar o momento da ovulação.

Palavras-chave: Imunoensaio. Progesterona. Saliva. Cadelas. Reprodução. 


\section{ABSTRACT}

LOPES, P. R. Evaluation of salivary progesterone in bitches during periovulatory period. [Avaliação da progesterona salivar em cadelas durante o período peri-ovulatório]. 2012. 65 f. Dissertação (Mestrado em Ciências) - Faculdade de Medicina Veterinária e Zootecnia, Universidade de São Paulo, São Paulo, 2012.

Several authors have already emphasized the importance of monitoring estrous cycle in bitches and mentioned examples of how it can be done. The aim of this study was to evaluate the salivary progesterone quantification technique in order to monitor the estrous cycle in this species. To compound the experimental group, 13 bitches were used. Blood and saliva samples were collected simultaneously in all animals, starting about the first day of proestrus signs. Salivary samples were collected with a specific device: Salivette ${ }^{\circledR}$. This method was effective, since it was possible to obtain enough volume in almost all samples to quantify progesterone. Serum progesterone was quantified by radioimmunoassay and salivary progesterone by enzyme immunoassay. Although there is an increasing, linear and positive correlation between salivary and serum progesterone $(r=0,704 ; p<0,0001)$, it is not possible to use the salivary parameter to set the moment of ovulation.

Keywords: Immunoassay. Progesterone. Saliva. Bitches. Reproduction. 


\section{SUMÁRIO}

1 INTRODUÇÃO

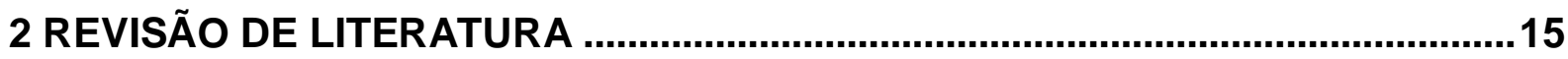

2.1 ASPECTOS REPRODUTIVOS DA CADELA......................................................15

2.2. PROGESTERONA E DOSAGENS HORMONAIS ..........................................18

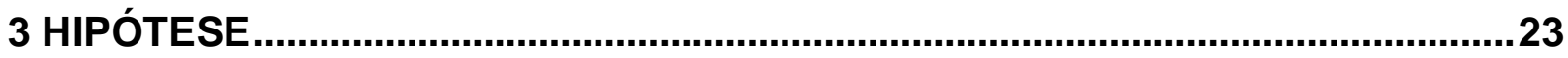

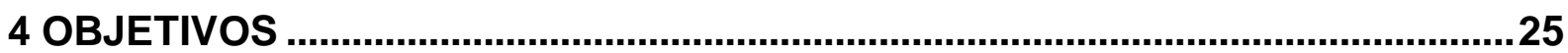

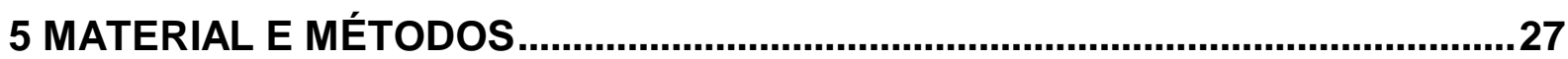

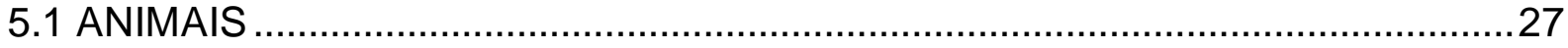

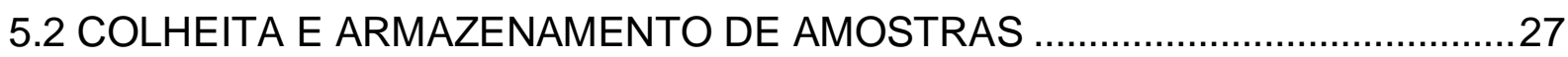

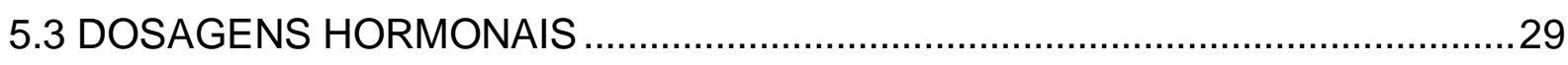

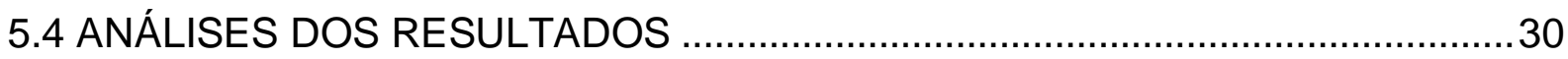

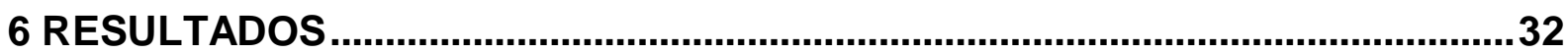

6.1 PARÂMETROS DE QUALIDADE DOS ENSAIOS HORMONAIS .........................32

6.2 VALIDAÇÃO LABORATORIAL DE CONJUNTO DIAGNÓSTICO COMERCIAL

PARA DOSAGEM DE PROGESTERONA SÉRICA EM CADELAS …........................33

6.3 VOLUMES DE SALIVA E QUANTIDADE DE AMOSTRAS …............................33

6.4 CORRELAÇÃO ENTRE PROGESTERONA SÉRICA E SALIVAR .......................34

6.5 PERFIL DA PROGESTERONA SÉRICA E SALIVAR .......................................35

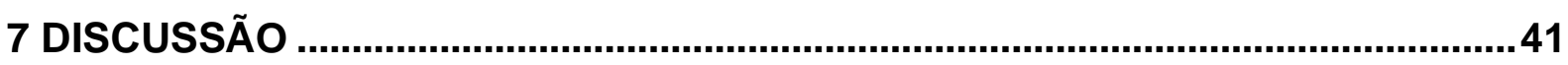

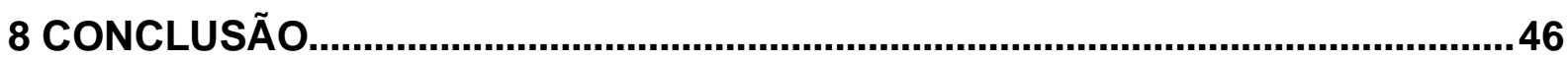

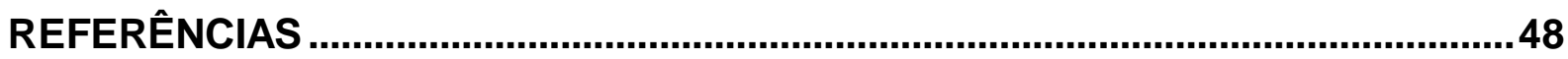

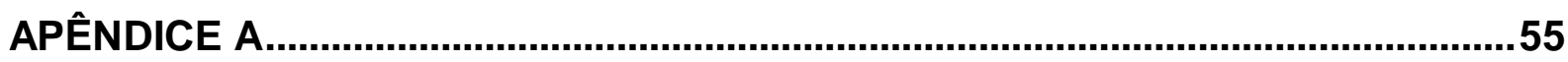


INTRODUÇÃO 


\section{INTRODUÇÃO}

O interesse na espécie canina e o conhecimento de suas particularidades reprodutivas aumentaram atualmente, pois, além de serem animais de companhia, são utilizados como modelos experimentais para outras espécies de canídeos (DERUSSI; LOPES, 2009).

A inseminação artificial (IA) é uma biotécnica que pode ser utilizada como meio alternativo quando há impossibilidade de realização de monta natural, devido a problemas anatômicos e comportamentais, ou ainda, quando há utilização de sêmen congelado. Apresenta ainda como vantagem a disseminação mais rápida do material genético de machos; preservação da sanidade de reprodutores; redução de custos e de estresse com transporte dos animais (SILVA; SILVA; CARDOSO, 2001).

Para o sucesso da $I A$, é imprescindível que se faça o correto acompanhamento do estro da cadela a ser inseminada. A determinação do momento ideal para inseminar é uma das chaves de sucesso e é tão mais importante quanto mais o sêmen sofre algum tipo de beneficiamento, pois a viabilidade espermática reduz-se com o resfriamento e ainda mais com a congelação (SILVA; SILVA; CARDOSO, 2001).

Para o acompanhamento do estro na cadela, a forma mais prática e usual é pela observação de seu comportamento sexual, associado à citologia vaginal. No entanto, uma grande parcela de cadelas candidatas à inseminação artificial são justamente aquelas que não manifestam comportamento sexual normal. Nesses casos, esse parâmetro não pode ser utilizado como guia, ficando a citologia vaginal como método isolado, que é excelente para guiar o médico veterinário dentro do ciclo estral da cadela, mas nem sempre eficaz quando utilizada isoladamente (SILVA; SILVA; CARDOSO, 2001). Não há mudanças significativas no esfregaço que indiquem o momento da onda pré-ovulatória do hormônio luteinizante (LH) ou da ovulação (SCHAEFERS-OKKENS, 2004).

Determinar o momento da ovulação na cadela não é simples e por isso é altamente recomendável a utilização de exames clínicos complementares (FANTBONNE, 2011). Vários métodos são descritos para este fim, sendo os principais a mensuração da concentração da progesterona no plasma e a 
vaginoscopia (SCHAEFERS-OKKENS, 2004). A vaginoscopia, porém, não permite determinar com acurácia o dia da ovulação (FANTBONNE, 2011).

A dosagem de LH nas cadelas, embora seja a alternativa ideal, não é realizada rotineiramente, pois é dispendiosa, consome tempo e não há ensaios comerciais disponíveis na maioria dos países, o que explica o fato de muitos pesquisadores e clínicos optarem pela mensuração das concentrações de progesterona sérica para estimar a ocorrência da ovulação (DERUSSI; LOPES, 2009; FENTBONNE, 2011).

A dosagem de progesterona é hoje uma prática rotineira (JOHNSTON; KUKUSTRITZ; OLSON, 2001). O radioimunoensaio (RIE) é uma técnica quantitativa da qual se obtém o valor exato da concentração de progesterona (LUZ, 2004).

O estudo da endocrinologia reprodutiva em animais domésticos é normalmente realizado com amostras sanguíneas, sendo necessárias em estudos mais profundos coletas seriadas com intervalos curtos. Em animais selvagens e animais de pequeno porte, essas coletas podem ficar impossibilitadas devido ao estresse causado pela contenção física e/ou química do animal (GUIMARÃES, 2003).

A partir dos conhecimentos sobre a distribuição dos esteróides pela corrente sanguínea, seu metabolismo e vias de excreção, vários trabalhos vêm sendo realizados sobre a fisiologia reprodutiva de animais utilizando diferentes matrizes biológicas (AMARAL, 2008). A dosagem da progesterona em fluidos biológicos é um indicador útil e preciso, sendo utilizada para controlar a atividade ovariana em diferentes espécies (CARREIRA; COLAÇO; SILVA, 2003). Amostras de saliva têm sido utilizadas na mensuração de esteróides reprodutivos femininos em diferentes espécies animais (CAMARGOS, 1989; FURTADO, 2007; PIRES, 2008). Sendo assim, a proposta deste trabalho é mensurar a progesterona de cadelas utilizando uma matriz biológica alternativa, a saliva, para monitorar o período peri-ovulatório. 
REVISÃO DE LITERATURA 


\section{REVISÃO DE LITERATURA}

A revisão de literatura foi redigida em dois tópicos, compreendendo: 1 aspectos reprodutivos da cadela; 2 - progesterona e dosagens hormonais.

\subsection{ASPECTOS REPRODUTIVOS DA CADELA}

O ciclo estral da cadela possui características distintas das de outras espécies. A cadela é uma espécie monoéstrica, predominantemente não sazonal, que apresenta quatro fases bem estabelecidas em seu ciclo estral: proestro, estro, diestro e anestro (HOFFMAN; RIESENBECK; KLEIN, 1996; JÖCHLE; ANDERSEN, 1977). O intervalo entre os ciclos reprodutivos é extremamente variável. Segundo Concannon, McCann e Temple (1989), a variação é de 5 a 12 meses. Estabelecer critérios para a identificação das fases do ciclo estral da cadela é essencial para se determinar o momento ideal para cobertura ou inseminação artificial (OLIVEIRA; MARQUES JR., 2006).

A duração do proestro é também bastante variável, podendo durar de 3 a 21 dias (CONCANNON; McCANN; TEMPLE, 1989). As cadelas apresentam edema e sangramento vaginal no começo do proestro e continuam apresentando estes sinais durante o estro. No proestro e estro, as fêmeas atraem os machos, mas não são receptivas na primeira fase (BEACH; DUNBAR; BUEHLER, 1982).

$A$ receptividade sexual na cadela é suportada na presença de concentrações em declínio de estrógenos e aumento continuado nas concentrações de progesterona (WILDT et al., 1979). Concannon et al. (1979) também sugeriram que são necessários declínios nas concentrações de estrógeno e aumento nas concentrações de progesterona na manifestação do comportamento sexual ao estudarem tal comportamento em cadelas ovariectomizadas em resposta a tratamentos com estrógeno e progesterona. Rota et al. (2007) mostraram diferenças 
significativas nas concentrações de progesterona e estradiol entre o primeiro dia da receptividade sexual e o dia anterior.

O principal evento hormonal durante o proestro é o aumento contínuo na concentração de estradiol sérico (OLIVEIRA; MARQUES JR., 2006). O aumento dos níveis de estrógeno no final do proestro inicia a onda pré-ovulatória de $\mathrm{LH}$ (CONCANNON; HANSEL; VISEK, 1975).

A fase de estro caracteriza-se pela redução na produção de estrógenos, aumento da secreção de progesterona, pico de LH, ovulação e desenvolvimento do corpo lúteo (CONCANNON; HANSEL; VISEK, 1975).

Benetti, Toniollo e Oliveira (2004) mostraram concentrações médias de progesterona elevando-se discretamente no final do proestro (de 1,56 para 2,85 $\mathrm{ng} / \mathrm{mL}$ ), concomitante com o início do declínio dos valores de estradiol no mesmo período (de 20,93 pg/mL para $18,81 \mathrm{pg} / \mathrm{mL}$ ).

A progesterona é secretada pelas células foliculares luteinizadas de folículos pré-ovulatórios e pelas células luteínicas de corpos lúteos. As cadelas apresentam luteinização folicular pré-ovulatória, que provoca elevações nos níveis de progesterona antes do pico pré-ovulatório de LH (LUZ, 2004).

Existe uma correlação entre as concentrações séricas de progesterona e o momento do pico pré-ovulatório de LH (LUZ, 2004), ou seja, o pico de LH pode ser estimado pela deteç̧ão de mudança nas concentrações de progesterona (GOODMAN, 2001). Concannon, Hansel e Mcentee (1977) relatam concentrações de 2,6 $\pm 0,3 \mathrm{ng} / \mathrm{ml}$ de progesterona no momento do pico de LH.

O pico de LH ocorre entre o último dia do proestro e os dois primeiros dias do estro (normalmente no primeiro dia do estro) e dura apenas 24 a 40 horas, retornando de imediato aos níveis basais. As ovulações ocorrem cerca de 48 horas após o pico de LH. A concentração plasmática de progesterona começa a subir gradualmente no fim do proestro, coincidindo com a queda na concentração de estrógenos, e aumenta de forma muito evidente após a ovulação. A relação entre as concentrações plasmáticas de progesterona e a evolução da fase folicular na cadela é a seguinte: $<1 \mathrm{ng} / \mathrm{mL}$ no anestro ou proestro; 1,0 a $1,9 \mathrm{ng} / \mathrm{mL}$ no dia anterior ao pico de LH; 2,0 a 2,9 ng/mL no dia do pico de $\mathrm{LH} ; 3,0$ a 3,9 $\mathrm{ng} / \mathrm{mL}$ no dia anterior a ovulação; 4,0 a 10,0 ng/mL no dia da ovulação; >10 ng/mL após a ovulação (ALVES et al., 2002). 
$\mathrm{Na}$ cadela, os oócitos são ovulados no estágio de oócito primário, imaturo, necessitando de dois a três dias de maturação até atingir o estágio de oócito secundário apto a ser fertilizado. O processo de ovulação pode durar 24 horas. Nos primeiros dois dias após a ovulação os oócitos se tornam maduros, ou seja, sofrem a primeira divisão meiótica e a extrusão do primeiro corpúsculo polar, após o qual a fertilização pode acorrer. A viabilidade dos oócitos maturados não é bem conhecida, mas provavelmente não excede 24 a 48 horas. Por esta razão, o período fértil da cadela situa-se entre os dias 2 e 5 após a ovulação (dias 4 e 7 após o pico de LH), devendo neste momento estar presente nos reservatórios do trato genital feminino uma população competente de espermatozoides (ALVES et al., 2002; SCHAEFERSOKKENS, 2004).

A principal função do corpo lúteo é a secreção de progesterona, que prepara o útero para o início e a manutenção da gestação (DAVIDSON; STABENFELDT, 1999). A progesterona de origem ovariana é necessária durante toda a gestação (CONCANNON; McCANN; TEMPLE, 1989), já que a placenta canina não secreta esteróides (KISO; YAMAUCHI, 1983).

Durante os primeiros 20-30 dias após a ovulação, o corpo lúteo é independente de suporte gonadotrófico. Na segunda metade do diestro ou gestação, - LH e principalmente a prolactina se tornam fatores luteotróficos essenciais (KOWALEWSKI et al., 2009).

O diestro termina em aproximadamente 60 dias, quando as concentrações de progesterona tornam-se mínima. Não há sinais clínicos que indicam o final do diestro (ALLEN, 1995). Diferentemente de outras espécies animais, a função lútea nas cadelas é quase idêntica nas fêmeas gestantes e não gestantes (HOFFMANN; RIESENBECK; KLEIN, 1996) e, por isso, não é possível utilizar a dosagem de progesterona para diagnóstico de gestação nesta espécie (FREITAS; SILVA, 2008).

As concentrações de progesterona durante a fase lútea caem para níveis de 0,3-0,4 ng/mL de 3 a 17 dias após hipofisectomia e aumentam após administração de LH, sugerindo que a função lútea normal na cadela depende de contínuo suporte hipofisário, envolvendo LH (CONCANNON, 1980; OKKENS et al., 1986).

A duração do anestro é variável, podendo durar de 1 a 8 meses (CONCANNON; McCANN; TEMPLE, 1989). Durante anos, o anestro foi considerado uma fase de repouso no ciclo reprodutivo da cadela, porém nem a hipófise nem os ovários encontram-se quiescentes nesse período. No início e meio do anestro, as 
concentrações de estradiol e progesterona encontram-se basais. Há elevação de estradiol no final do anestro (OLIVEIRA; MARQUES JR., 2006).

\subsection{PROGESTERONA E DOSAGENS HORMONAIS}

A progesterona é um hormônio esteróide com 21 átomos de carbono, considerada o principal hormônio da família das progestinas. Sua síntese ocorre pela conversão do colesterol em pregnenolona e desta em progesterona. As principais enzimas envolvidas nessas reações são a $P 450_{s c c}$ e a $3 \beta$-hidroxiesteróide desidrogenase (3$\left.\beta_{\mathrm{HSD}}\right)$ (NORMAN; LITWACK, 1997).

A dosagem de progesterona pode ser feita por RIE ou por kits comerciais quantitativos e qualitativos de ELISA (enzyme-linked immunoassay) (ENGLAND; ALLEN; PORTER, 1989). O RIE é uma técnica mais acurada, porém é mais cara e requer maior tempo de execução (JOHNSTON; KUKUSTRITZ; OLSON, 2001).

O RIE, um dos maiores avanços na endocrinologia analítica, permite rápida medida de grande número de amostras contendo pequenas concentrações de hormônios. O RIE se baseia no uso de um agente ligante específico e de hormônios radioativos como traçadores, para medir a concentração de substâncias. Segundo os princípios desse método, uma quantidade fixa de hormônio radioativo compete com o hormônio a ser medido por um número limitado de sítios de ligação de um agente ligante de alta afinidade e especificidade pelo hormônio em questão (HAFEZ, 1995; THOREL; LARSON, 1978; RODINI, 2008).

A dosagem de progesterona por RIE pode ser realizada tanto pela técnica em fase sólida, sem extração, quanto pela técnica com extração, sendo que ambas são confiáveis a convenientes para monitorar a função lútea em cadelas (SRIKANDAKUMAR et al., 1986).

A quantificação de progesterona em soro canino utilizando enzimaimunoensaio (EIE) apresenta boa correlação $(r=0,91, p<0,001)$ com os resultados obtidos por RIE (VERVERIDIS et al., 2002). 
Utilizadas em diferentes espécies, as técnicas de monitoramento não invasivo consistem na extração de hormônios e seus metabólitos de diferentes matrizes biológicas como fezes, urina, leite, saliva e pêlos. Na espécie canina, é possível, por exemplo, determinar as concentrações do hormônio testosterona no pêlo (CALAMARI, 2008).

Saliva, suor e lágrima podem ser utilizados para fins diagnósticos (HAECKEL; HÄNECKE, 1993). A saliva, por ser um biofluido facilmente acessível e informativo, é ideal para fins diagnósticos, detecção precoce de uma ampla gama de doenças (SUGIMOTO et al., 2010). A utilização de saliva apresenta vantagens sobre a utilização de soro para tais fins, pois pode ser coletada de forma não invasiva, por indivíduos com pouco treinamento, em situações em que há dificuldade em se obter amostras sanguíneas (HOFMAN, 2001; PFAFFE et al., 2011).

A saliva é utilizada principalmente para dosagens hormonais, especialmente de esteróides (HAECKEL; HÄNECKE, 1993). A dosagem de esteróides salivares é considerada um método não estressante e não invasivo (GRÖSCHL; RAUH; DÖRR, 2003).

A saliva é um fluido de fácil obtenção que pode ser usado pra monitorar a concentração de uma ampla variedade de hormônios (KIESS; PFAEFFLE, 2007). Os testes altamente sensíveis, que são atualmente rotineiros, tornam prático quantificar, apesar de concentrações muito baixas, um grande número de hormônios na saliva (MANDEL, 1990). Anticorpos para mensuração de progesterona em saliva de mulheres por EIE já foram desenvolvidos e validados (O'RORKE et al., 1994).

A composição da saliva varia de acordo com o fluxo salivar e pode se alterar em função da idade e variações hormonais decorrentes de condições clínico/fisiológicas (PIRES, 2008). Embora haja uma grande variabilidade individual nas taxas do fluxo salivar, as concentrações de esteróides na saliva não dependem dessa taxa (BOEVER et al., 1990; PIRES, 2008). A progesterona é metabolicamente estável na saliva (LEWIS, 2006).

Em cães, já foi demonstrada uma correlação estatisticamente significante entre os níveis de cortisol sérico e salivar (VINCENT; MICHELL, 1992).

Há várias questões envolvidas na coleta de saliva que devem ser consideradas, como material de coleta, volume de saliva coletado, uso de estimulantes salivares, efeito da contaminação por alimentos. Geralmente a coleta de saliva em cães envolve manter um rolo de algodão em suas bocas por um a dois 
minutos. A saliva é então extraída pela compressão do algodão saturado em uma seringa de $5 \mathrm{~mL}$ ou centrifugada em um dispositivo Salivette ${ }^{\circledR}$ (Sarstedt, NC). Esponjas cirúrgicas oftálmicas feitas de hidrocelulose são efetivas em absorver saliva e rendem bem quando centrifugadas. Foi sugerido, em estudos anteriores, que o uso de algodão aromatizado ajudaria na coleta de saliva em cães, porém partículas alimentares podem conter substâncias que causam reação cruzada com os anticorpos usados em imunoensaios levando a falsos resultados na dosagem de muitos hormônios (DRESCHEL, 2009).

O uso de materiais de algodão para coleta de saliva interfere nos resultados de imunoensaios. Os resultados são artificialmente altos nas dosagens de progesterona quando o algodão é utilizado para absorver saliva durante a coleta (SHIRTCLIFF et al., 2001).

A concentração de progesterona varia nas diferentes amostras em que pode ser dosada (soro, plasma, leite, saliva e outros fluidos corporais), pelo que se torna necessário validar os resultados obtidos para os diferentes tipos de amostra a utilizar, de forma a garantir uma uniformidade de apreciação dos resultados (CARREIRA et al., 2004).

As concentrações de progestinas fecais possuem uma baixa correlação quando comparada a fase do ciclo estral em cadelas (SILVA, 2005).

A correlação entre progesterona sérica e salivar já foi demonstrada em diferentes espécies animais. A correlação focas-monge-do-havaí é 0,868 (PIETRASZEK; ATKINSON, 1994); em ovelhas, 0,90 (FURTADO, 2007); em vacas, 0,85 (GAO; SHORT; FLETCHER, 1988).

Há correlação entre concentrações de progesterona no soro e saliva em mulheres ao longo dos trimestres gestacionais e nas fases folicular e lútea em não gestantes (PIRES, 2008). A dosagem de progesterona salivar é uma ferramenta útil para avaliar a função lútea na mulher (ISHIKAWA et al., 2002).

É importante lembrar que o metabolismo e excreção de esteróides diferem entre espécies e desta maneira os métodos não invasivos devem ser rigorosamente validados para cada espécie antes de sua utilização (PALME, 2005).

$O$ estudo da endocrinologia de forma não invasiva poderá ser usado no monitoramento da função reprodutiva das fêmeas, acasalamento ou IA, além de que, o conhecimento e a aplicação de técnicas de biotecnologia caminham lado a 
lado aos programas de conservação de canídeos não domésticos (GOODROWE et al., 2000). 
HIPÓTESE 


\section{HIPÓTESE}

Existe correlação positiva entre a concentração sérica e salivar de progesterona em cadelas. 


\section{OBJETIVOS}




\section{OBJETIVOS}

- validar laboratorialmente o conjunto diagnóstico comercial Immunotech ${ }^{\circledR}$ (Beckman Coulter Company, Marseille, France) para quantificação de progesterona em soro de cadelas por RIE.

- avaliar o uso do dispositivo Salivette ${ }^{\circledR}$ (Sarstedt, NC) para coleta de saliva em cadelas para dosagem de progesterona.

- verificar se há correlação entre as concentrações sérica e salivar de progesterona em cadelas.

- validar o conjunto diagnóstico comercial Salimetrics® (State College, PA, USA) para quantificação de progesterona na saliva de cadelas por EIE.

- determinar a aplicabilidade da técnica de dosagem de progesterona salivar em cadelas para predizer o momento da ovulação e monitorar o período peri-ovulatório da espécie. 
MATERIAL E MÉTODOS 


\section{MATERIAL E MÉTODOS}

\subsection{ANIMAIS}

Para composição do grupo experimental, foram utilizadas 13 cadelas de diferentes idades e pesos, sendo seis $(46,2 \%)$ da raça Buldogue (cadelas C1 a C6), duas (15,4\%) da raça Bernesse Mountain Dog (C7 e C8) e cinco (38,5\%) SRD (sem raça definida) (C9 a C13), todas hígidas e não castradas.

\subsection{COLHEITA E ARMAZENAMENTO DE AMOSTRAS}

As amostras de sangue e saliva foram colhidas paralelamente em todos os animais, a partir dos primeiros sinais de proestro, como edema vulvar e descarga vaginal sanguinolenta. A quantidade de amostras por animal foi de 1 a 15 , com média de 6 amostras por animal, totalizando 83 amostras de sangue e 83 amostras de saliva. $O$ intervalo entre as coletas foi de 1 a 7 dias, com média de 2 dias de intervalo entre as coletas. Em duas das treze cadelas foram coletadas amostras em dois cios sequenciais, totalizando 15 momentos peri-ovulatórios.

As amostras foram devidamente identificadas e armazenadas em freezer a $-20^{\circ} \mathrm{C}$ até a etapa subsequente de dosagem hormonal.

As colheitas de sangue foram realizadas através da punção de veia jugular, cefálica ou safena, após antissepsia, com seringas descartáveis de $5 \mathrm{~mL}$ e agulhas hipodérmicas $25 \times 8$, utilizando-se tubos com gel separador. Os tubos foram centrifugados a $1500 \mathrm{~g}$ por 15 minutos e o soro obtido foi acondicionado em microtubos de $1,5 \mathrm{~mL}$ de polietileno, devidamente identificados. 
As amostras salivares foram obtidas com o uso de dispositivo de poliéster específico para coleta de saliva Salivette ${ }^{\circledR}$ (Sarstedt, NC) (Figura 1). O swab de poliéster foi inserido na boca dos animais (Figura 2) por cerca de dois minutos e introduzido no tubo plástico, que então foi centrifugado a $1500 \mathrm{~g}$ por 15 minutos. A saliva resultante era acondicionada em microtubos de $1,5 \mathrm{~mL}$ de polietileno, devidamente identificados.

Figura 1 - Dispositivo comercial Salivette ${ }^{\circledR}$ para coleta de saliva

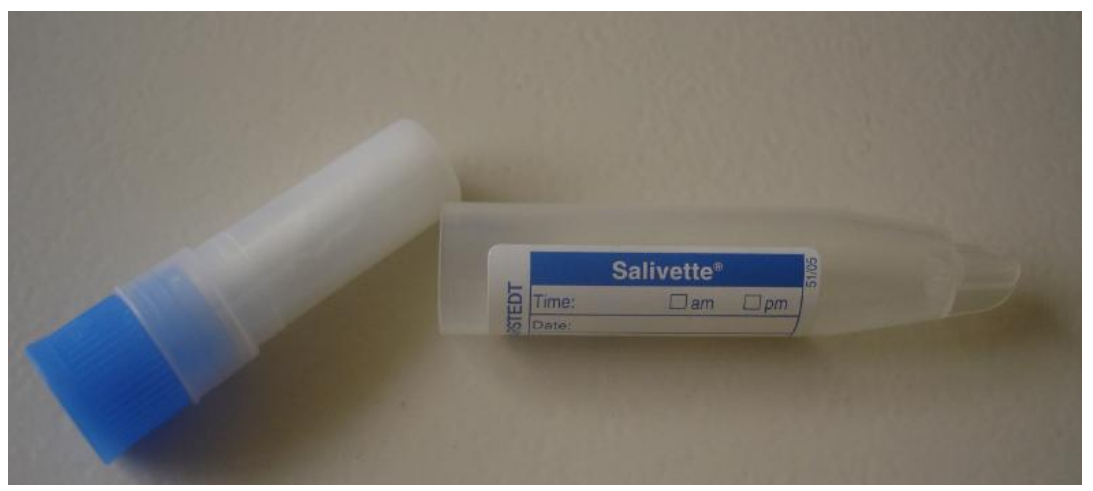

Figura 2 - Coleta de saliva em uma cadela da raça Buldogue

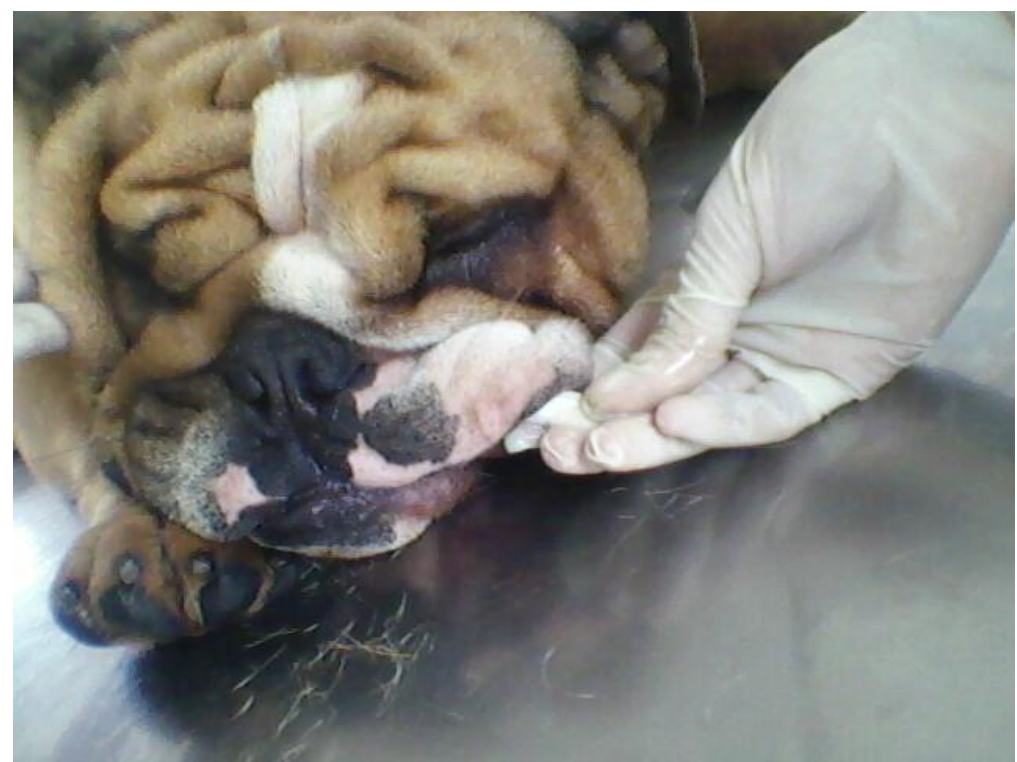




\subsection{DOSAGENS HORMONAIS}

As concentrações de progesterona das amostras foram determinadas no Laboratório de Dosagens Hormonais (LDH), do Departamento de Reprodução Animal da Faculdade de Medicina Veterinária e Zootecnia da Universidade de São Paulo.

As concentrações de progesterona no soro foram determinadas pela técnica de RIE em fase sólida utilizando-se os conjuntos diagnósticos comerciais desenvolvidos para dosagem hormonal de progesterona em soro humano Coat-ACount $^{\circledR}$ (Siemens, Los Angeles, CA, USA), já validado para dosagem de progesterona sérica na espécie canina (SRIKANDAKUMAR et al., 1986); e Immunotech ${ }^{\circledR}$ (Beckman Coulter Company, Marseille, France).

Estes conjuntos diagnósticos utilizam como elemento traçador o hormônio marcado com ${ }^{125}$ I e apresentam pouca reação cruzada com os metabólitos da progesterona.

As amostras de saliva passaram por dois ciclos de congelamento e descongelamento e posterior centrifugação a $2500 \mathrm{~g}$ por 10 minutos para remoção de resíduos.

A progesterona salivar foi dosada pela técnica de EIE utilizando o conjunto diagnóstico comercial Salimetrics ${ }^{\circledR}$ (State College, PA, USA) desenvolvido para dosagem hormonal de progesterona em saliva humana.

Todas as etapas laboratoriais foram realizadas de acordo com as metodologias propostas pelos fabricantes dos conjuntos diagnósticos comerciais. Todos os parâmetros de controle de qualidade dos ensaios hormonais foram analisados conforme rotina empregada no $\mathrm{LDH}$, ou seja, foram calculados os coeficientes de variação intra e inter-ensaio, utilizando valores altos e baixos, no início e fim de cada ensaio (AMARAL, 2008; FURTADO, 2007; RODINI, 2008).

As amostras foram dosadas em duplicata. As concentrações de progesterona sérica e salivar foram expressam em $\mathrm{ng} / \mathrm{mL}$ e/ou $\mathrm{pg} / \mathrm{mL}$. 


\subsection{ANÁLISES DOS RESULTADOS}

As análises estatísticas e os gráficos foram realizados utilizando os programas SPSS 19.0 (@ SPSS, Inc.); Statview 5.1. (๑ SAS, Inc.) e Excel (๑ Microsoft).

Os dados foram testados quanto à normalidade pelo teste de Shapiro-Wilk. O teste de correlação de Pearson foi utilizado para verificar a relação entre as variáveis paramétricas. Os resultados foram expressos através do coeficiente de correlação (r), adotando-se como nível de significância $p=5 \%$.

Para descrição dos resultados, foram empregadas as médias e seus respectivos erros padrões dos dados originais. As médias foram comparadas utilizando-se análise de variância para medidas repetidas. 
RESULTADOS 


\section{RESULTADOS}

Os resultados obtidos são apresentados a seguir.

\subsection{PARÂMETROS DE QUALIDADE DOS ENSAIOS HORMONAIS}

O controle de qualidade dos ensaios de RIE foi realizado através da análise dos coeficientes de variação intra-ensaio e inter-ensaio, que foram inferiores a $10 \%$ e sensibilidade mínima detectada, que foi de $0,003 \mathrm{ng} / \mathrm{mL}$ e $0,004 \mathrm{ng} / \mathrm{mL}$ nos dois ensaios realizados (Tabela 1).

Tabela 1 - Controle de qualidade obtido nos ensaios hormonais de progesterona sérica

\begin{tabular}{ccccccc}
\hline & CPM & Cap. Lig. & L.N.E & Sensibilidade & CV Intra & CV Intra \\
ENSAIO & total & B/BO & $(\%)$ & $\%($ dose $n g / m L)$ & Baixo & Alto \\
\hline 1 & 48816 & $55 \%$ & 186 & $93(0,003)$ & $8,42 \%$ & $2,49 \%$ \\
2 & 50485 & $48 \%$ & 375 & $92(0,004)$ & $9,70 \%$ & $3,87 \%$ \\
CV Inter ensaio & & & & & $8,42 \%$ & $2,48 \%$ \\
\hline
\end{tabular}

\section{Legenda:}

CPM: contagens por minuto

Cap. Lig.: capacidade de ligação

L.N.E.: ligação não específica

CV intra: coeficiente de variação intra-ensaio

CV inter: coeficiente de variação inter-ensaio

O controle de qualidade dos ensaios de EIE foi realizado através da análise dos coeficientes de variação intra-ensaio baixo e alto, que foram 6,33\% e 2,55\%, respectivamente; sensibilidade mínima detectada, que foi de $5,042 \mathrm{pg} / \mathrm{mL}$; e capacidade de ligação B/B0 que foi de $92 \%$. 


\subsection{VALIDAÇÃO LABORATORIAL DE CONJUNTO DIAGNÓSTICO COMERCIAL PARA DOSAGEM DE PROGESTERONA SÉRICA EM CADELAS}

A validação laboratorial do conjunto diagnóstico comercial Immunotech ${ }^{\circledast}$ para quantificação de progesterona sérica em cadelas foi realizada pelo cálculo da correlação existente entre os resultados obtidos com esse kit e os obtidos com o kit Coat-a-Count ${ }^{\circledR}$.

O coeficiente de correlação (Person) obtido foi $r=0,99$ (intervalo de confiança de $95 \%)$.

\subsection{VOLUMES DE SALIVA E QUANTIDADE DE AMOSTRAS}

Não foi possível obter volume de saliva suficiente para dosagem de progesterona em sete $(8,4 \%)$ amostras. O conjunto diagnóstico utilizado para quantificação requer o volume de $50 \mu \mathrm{L}$ de saliva para dosagem de progesterona, ou seja, $100 \mu \mathrm{L}$ de saliva para dosagem em duplicata. Então, entre as 83 amostras obtidas, sete possuíam volume inferior a $100 \mu \mathrm{L}$, restando 76 amostras para 0 estudo. A média de volumes de saliva obtidos nestas amostras foi de 220,3 $\mu \mathrm{L}$. 


\subsection{CORRELAÇÃO ENTRE PROGESTERONA SÉRICA E SALIVAR}

O teste de correlação de Pearson foi utilizado para verificar a relação entre as dosagens sérica e salivar de progesterona. Para esta análise foi utilizado $n=76$. Há uma relação linear crescente, positiva e forte com coeficiente de correlação $r=0,704$ $(p<0,0001)$. $A$ análise de regressão entre matriz sérica e salivar encontra-se no gráfico 1.

Gráfico 1 - Representação gráfica da regressão linear entre as matrizes sérica e salivar na dosagem de progesterona

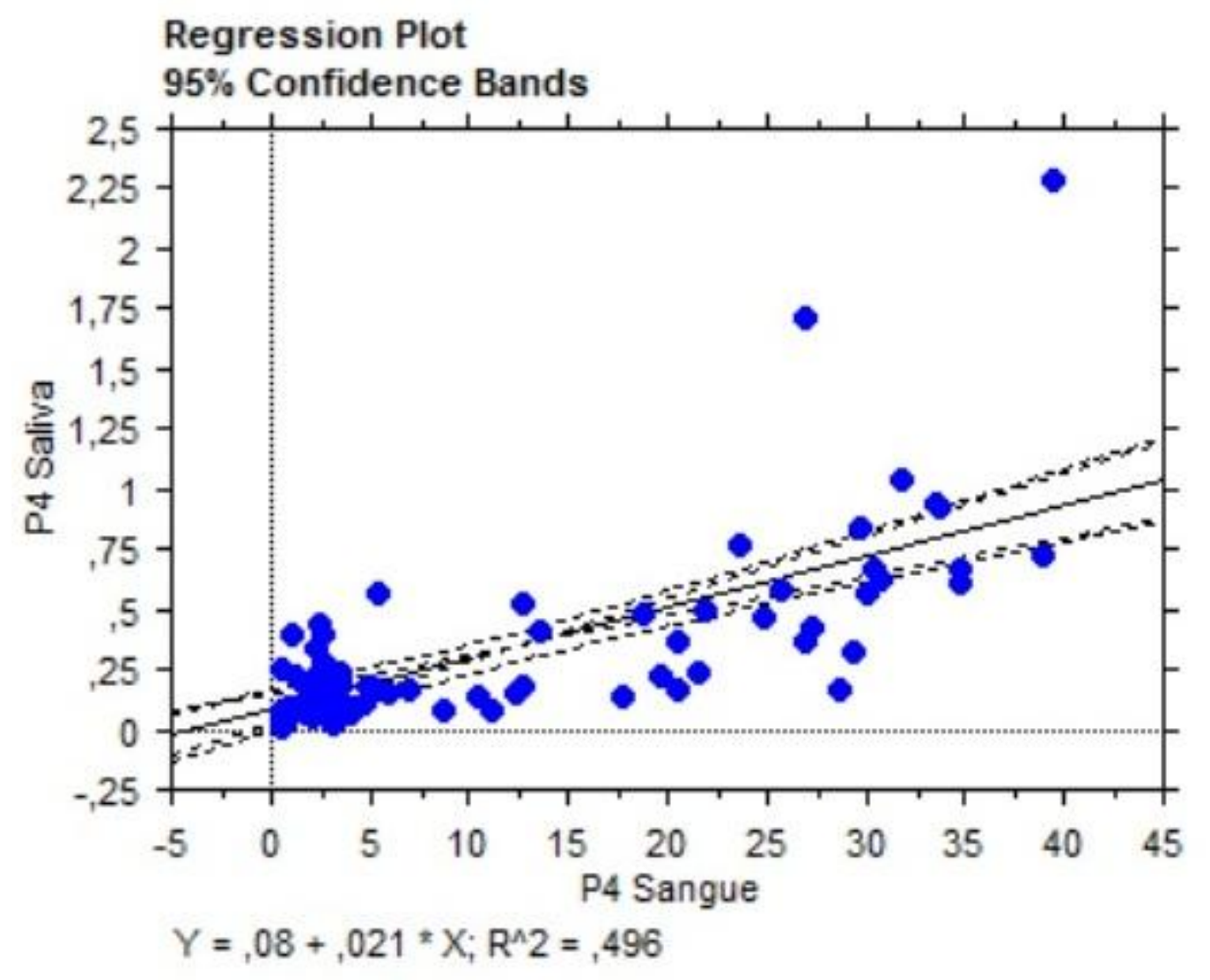




\subsection{PERFIL DA PROGESTERONA SÉRICA E SALIVAR}

Os resultados referentes às dosagens séricas e salivares de progesterona estão demonstrados nas tabelas e figuras a seguir.

Para alinhamento dos períodos peri-ovulatórios dos animais, o início da ovulação (D0) em cada período foi considerado o dia em que foi efetivamente obtido o primeiro valor acima de $4 \mathrm{ng} / \mathrm{mL}$ na concentração de progesterona sérica ou estimado através dos pontos imediatamente anterior e posterior a este valor.

Os perfis da progesterona sérica e salivar foram obtidos através das médias das concentrações deste hormônio, em cada uma das matrizes biológicas, nos animais $\mathrm{C} 1, \mathrm{C} 2, \mathrm{C} 3, \mathrm{C} 4, \mathrm{C} 5, \mathrm{C} 8, \mathrm{C} 9, \mathrm{C} 10, \mathrm{C} 12$, totalizando 9 animais. Nos animais C3 e C10 foram analisados dois cios subsequentes, totalizando 11 períodos periovulatórios. Os resultados individuais destes animais estão apresentados no anexo A deste trabalho. Nos outros animais não foi possível determinar o início da ovulação (D0) devido ao número insuficiente de amostras obtidos de C6 e C11 (duas amostras) e de $\mathrm{C} 13$ (apenas uma amostra), todas com valores inferiores a $1 \mathrm{ng} / \mathrm{mL}$, e devido ao fato de que em C7 os níveis de progesterona não se elevaram durante os 15 dias consecutivos de coleta, caracterizando um período peri-ovulatório atípico (Gráfico 2).
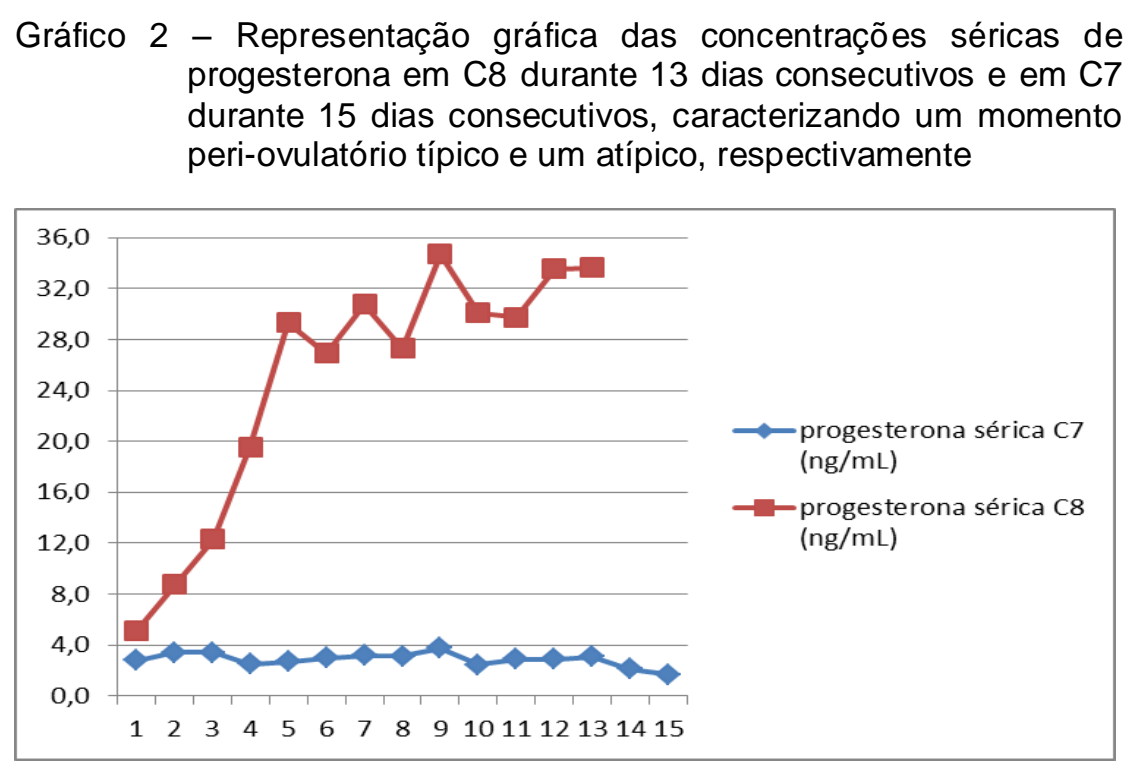
A tabela 2 apresenta as médias dos resultados obtidos referentes às concentrações séricas de progesterona dos nove animais em onze períodos periovulatórios, com seus respectivos desvios padrão e erros padrão. O gráfico 3 apresenta as médias e seus respectivos erros padrão desses resultados.

Os valores médios de progesterona sérica elevaram-se a partir de D2 $(\mathrm{p}<0,05)$.

Tabela 2 - Médias e seus respectivos desvios padrão (d.p) e erros padrão (e.p.) das concentrações séricas de progesterona $(\mathrm{ng} / \mathrm{mL})$ obtidas de nove cadelas ao longo de onze períodos periovulatórios, considerando D0 o dia em que foi efetivamente obtido o primeiro valor acima de $4 \mathrm{ng} / \mathrm{mL}$ ou estimado através dos pontos imediatamente anterior e posterior a este valor

\begin{tabular}{cccccc}
\hline medidas & $\mathrm{n}$ & média & d.p. & e.p. \\
\hline D-3 & 2 & 0,89 & 0,55 & 0,39 & $\mathrm{a}$ \\
D-2 & 3 & 2,05 & 0,33 & 0,19 & $\mathrm{a}$ \\
D-1 & 3 & 2,59 & 0,66 & 0,38 & $\mathrm{a}$ \\
D0 & 5 & 4,66 & 0,42 & 0,19 & $\mathrm{a}$ \\
D1 & 3 & 6,73 & 1,78 & 1,03 & $\mathrm{a}$ \\
D2 & 8 & 12,83 & 6,43 & 2,27 & $\mathrm{~b}$ \\
D3 & 3 & 20,63 & 7,65 & 4,42 & $\mathrm{~b}$ \\
D4 & 3 & 24,17 & 9,91 & 5,73 & $\mathrm{~b}$ \\
D5 & 4 & 23,64 & 3,96 & 1,98 & $\mathrm{~b}$ \\
D6 & 2 & 25,60 & 7,29 & 5,17 & $\mathrm{~b}$ \\
D7 & 4 & 27,91 & 7,85 & 3,93 & $\mathrm{~b}$ \\
D8 & 2 & 28,11 & 9,31 & 6,60 & $\mathrm{~b}$ \\
D9 & 2 & 30,97 & 1,24 & 0,88 & $\mathrm{~b}$ \\
D10 & 2 & 32,25 & 3,56 & 2,52 & $\mathrm{~b}$ \\
\hline
\end{tabular}


Gráfico 3 - Representação gráfica do comportamento das médias e seus respectivos erros padrão das medidas de progesterona sérica em 9 cadelas e 11 períodos periovulatórios, considerando D0 o dia em que foi efetivamente obtido o primeiro valor acima de $4 \mathrm{ng} / \mathrm{mL}$ ou estimado através dos pontos imediatamente anterior e posterior a este valor

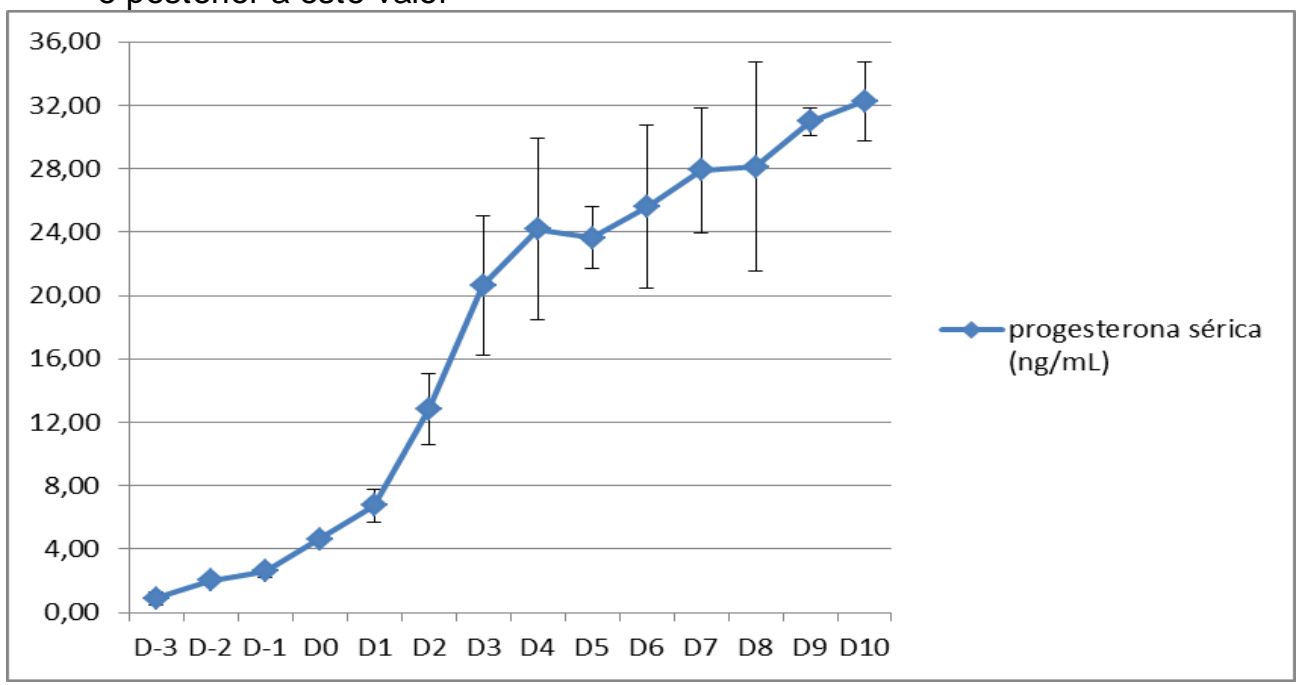

A tabela 3 apresenta as médias dos resultados obtidos referentes às concentrações salivares de progesterona dos nove animais em onze períodos periovulatórios, com seus respectivos desvios padrão e erros padrão. $O$ gráfico 4 apresenta as médias e seus respectivos erros padrão desses resultados.

Os valores médios de progesterona salivar elevaram-se em D5, mas declinaram em D6, voltando a elevarem-se em D9 $(p<0,05)$. 
Tabela 3 - Médias e seus respectivos desvios padrão (d.p) e erros padrão (e.p.) das concentrações salivares de progesterona $(\mathrm{ng} / \mathrm{mL}$ ) obtidas de nove cadelas ao longo de onze períodos peri-ovulatórios, considerando D0 o dia em que foi efetivamente obtido o primeiro valor acima de $4 \mathrm{ng} / \mathrm{mL}$ na concentração sérica de progesterona ou estimado através dos pontos imediatamente anterior e posterior a este valor

\begin{tabular}{ccccccr}
\cline { 1 - 4 } medidas & $\mathrm{n}$ & média & d.p. & e.p. & & \\
\cline { 1 - 5 } D-3 & 2 & 136,71 & 123,45 & 87,55 & a \\
D-2 & 3 & 227,89 & 195,61 & 113,07 & a \\
D-1 & 3 & 240,15 & 144,59 & 83,58 & a \\
D0 & 5 & 125,58 & 53,57 & 23,92 & a \\
D1 & 3 & 264,89 & 265,83 & 153,66 & a \\
D2 & 8 & 242,94 & 194,18 & 68,61 & a \\
D3 & 3 & 262,68 & 132,27 & 76,45 & a \\
D4 & 3 & 386,58 & 244,66 & 141,42 & b \\
D5 & 4 & 762,40 & 633,64 & 316,82 & a \\
D6 & 2 & 398,86 & 319,86 & 226,85 & a \\
D7 & 4 & 494,63 & 159,88 & 79,94 & a \\
D8 & 2 & 446,78 & 297,00 & 210,64 & b \\
D9 & 2 & 803,82 & 335,16 & 237,70 & b \\
D10 & 2 & 723,95 & 159,44 & 113,08 & b
\end{tabular}

Gráfico 4 - Representação gráfica do comportamento das médias das medidas de progesterona salivar em 9 cadelas e 11 períodos peri-ovulatórios, considerando D0 o dia em que foi obtido o primeiro valor acima de $4 \mathrm{ng} / \mathrm{mL}$ na concentração de progesterona sérica

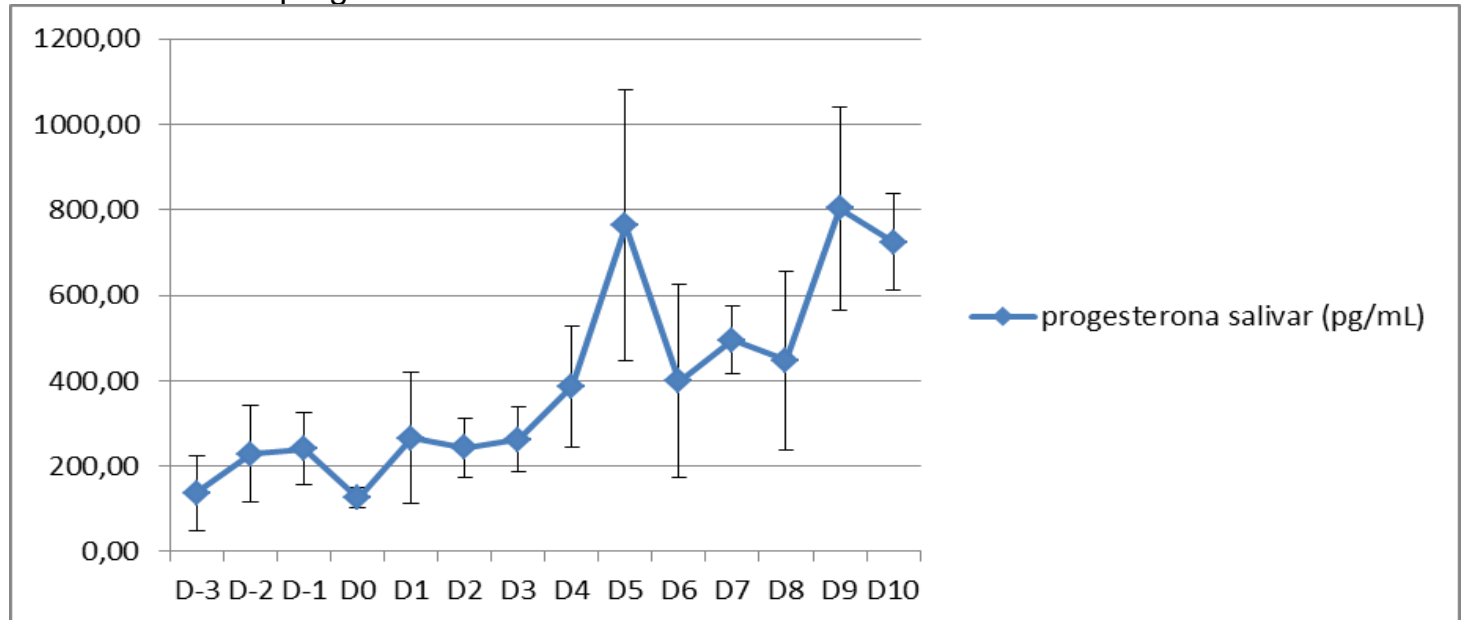

O gráfico 5 apresenta as médias e seus respectivos erros padrão dos resultados obtidos referentes às concentrações séricas e salivares de progesterona dos nove animais em onze períodos peri-ovulatórios. 
Gráfico 5 - Representação gráfica do comportamento das médias das concentrações séricas e salivares de progesterona em 9 cadelas e 11 períodos peri-ovulatórios, considerando D0 o dia em que foi obtido o primeiro valor acima de $4 \mathrm{ng} / \mathrm{mL}$ na concentração sérica de progesterona. As setas indicam os momentos em que aconteceram os primeiros aumentos significativos nas concentrações de progesterona sérica (primeira seta, da esquerda para a direita) e salivar (segunda seta, da esquerda para a direita)

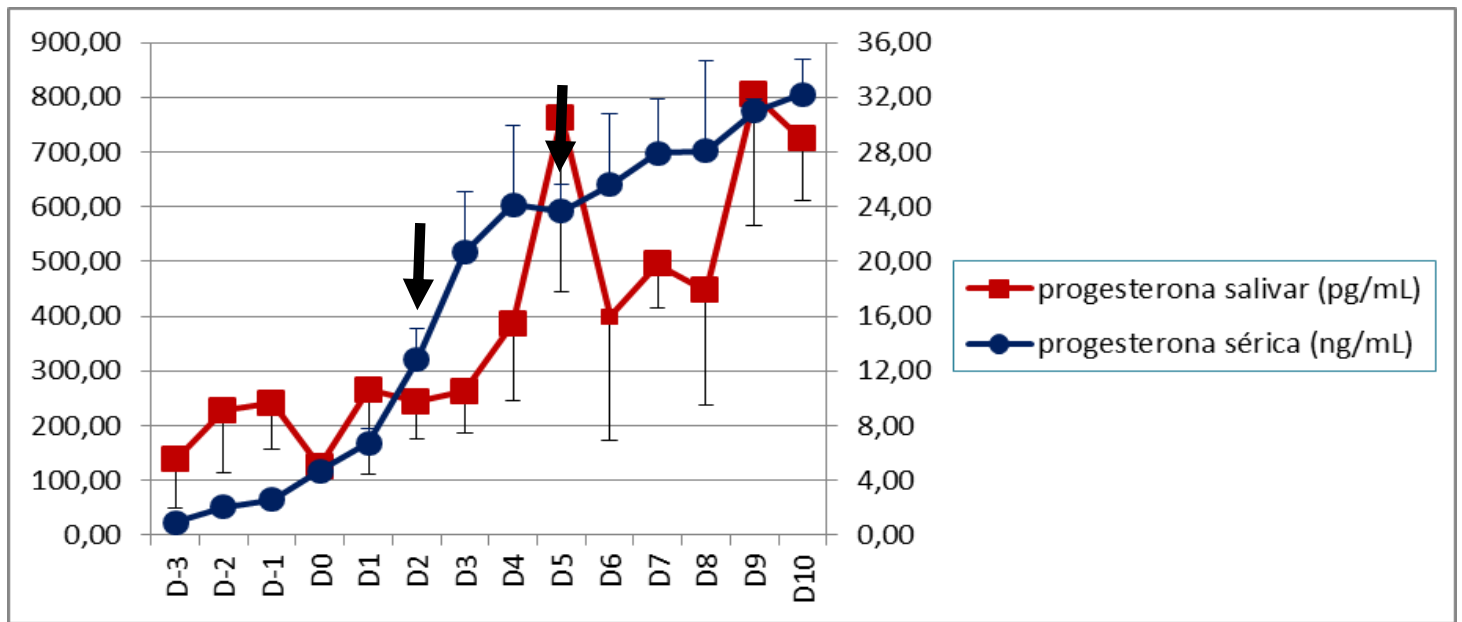




\section{DISCUSSÃO}




\section{DISCUSSÃo}

Vários autores já enfatizaram a importância do monitoramento do ciclo estral em cadelas e citaram exemplos de como ele pode ser feito (SILVA; SILVA; CARDOSO, 2001; LUZ, 2004; SCHAEFERS-OKKENS, 2004; OLIVEIRA; MARQUES JR., 2006). Este trabalho, além de se objetivar a validação de um novo conjunto diagnóstico comercial para uma técnica já rotineira de monitoramento, a dosagem de progesterona sérica por RIE, é o primeiro trabalho a propor o uso de uma matriz biológica alternativa, a saliva, para monitoração do ciclo estral em cadelas.

De acordo com o resultado (índice de correlação) obtido, foi realizada a validação laboratorial do conjunto diagnóstico comercial Immunotech ${ }^{\circledR}$ para uso em amostras séricas de cadelas para dosagem de progesterona. Este conjunto comercial apresenta como vantagem um menor tempo de incubação, apenas uma hora, o que permite aos laboratórios especializados em dosagens hormonais por RIE aumentar a eficiência na dosagem deste hormônio nesta espécie.

O perfil hormonal de progesterona sérica mostrou crescentes concentrações do hormônio ao longo do tempo com aumento significativo a partir de D2, momento em que a progesterona atinge concentrações séricas de $12,83 \mathrm{ng} / \mathrm{mL}$. Estes resultados contrariam, em parte, os obtidos por Concannon, Hansel e Visek (1975), que observaram concentrações de progesterona crescentes significativas $(p<0,001)$ de 0,8 a 2,6 $\mathrm{ng} / \mathrm{mL}$ em um intervalo de dois dias.

Um estudo feito por Rota et al. (2007) obteve diferença estatística significativa nas concentrações de progesterona entre o dia anterior e o primeiro dia de receptividade sexual, mas não na transição entre o final do estro e começo do diestro. O trabalho de Wildt et al. (1979) encontrou aumento significativo nas concentrações de progesterona no dia do pico de LH.

As diferenças dos resultados obtidos entre este trabalho e os supracitados devem-se às diferenças metodológicas neles empregadas e às elevadas variações interindividuais. No trabalho de Concannon, Hansel e Visek (1975), por exemplo, foram utilizadas 20 cadelas e as coletas sanguíneas ocorreram diariamente, o que possibilitou uma maior amostra estatística. 
Houve uma cadela que, após manifestar sinais de proestro, não apresentou aumento nas concentrações séricas de progesterona. Para explicar o ocorrido, podemos citar algumas hipóteses. Embora raro, pode ser que a cadela apresentou um ciclo anovulatório. De acordo com Fentbonne (2011), nestes casos, os níveis séricos de progesterona nunca se elevam mais do que 3,5-6,0 ng/mL, devido a níveis muito elevados de estradiol, o que não permite a ocorrência do pico de LH. Este evento pode acontecer nos casos de cistos foliculares ou devido a um proestro muito prolongado. Segundo Allen (1995), em algumas fêmeas, o primeiro proestro não evolui para estro e pode terminar em três ou mais semanas. Nesses casos não há maturação folicular devido a uma insuficiente estimulação hipofisária. Segundo o autor, fêmeas com proestro e estro normal raramente apresentam falhas de ovulação.

O método utilizado neste estudo para obtenção de saliva em cadelas, o uso do dispositivo específico para coleta Salivette ${ }^{\circledR}$, mostrou-se eficaz, visto que foi possível obter volume suficiente para dosagem de progesterona na grande maioria das amostras $(91,6 \%)$. Além disso, de acordo com Gröschl e Rauh (2006), entre os dispositivos comerciais para coleta de saliva, apenas o Salivette $\AA$ de poliéster é adequado para análise de esteróides salivares.

Como já relatado em outras espécies (GAO; SHORT; FLETCHER, 1988; PIETRASZEK; ATKINSON, 1994; FURTADO, 2007; PIRES, 2008), a correlação entre progesterona sérica e salivar na cadela é também forte e positiva, confirmando a hipótese deste trabalho.

De acordo com Palme (2005) os métodos não invasivos devem ser rigorosamente validados para cada espécie antes de sua utilização. Nosso estudo validou a técnica de quantificação de progesterona salivar em cadelas por EIE utilizando o conjunto diagnóstico comercial Salimetrics ${ }^{\circledR}$. Esta técnica apresenta vantagens quando comparada com a tradicional técnica de dosagem sérica de progesterona por RIE.

O RIE utiliza material radioativo, o que requer licenças especiais junto aos órgãos reguladores. Com o desenvolvimento de programas de responsabilidade ambiental, foram desenvolvidas alternativas a esse método radioativo para a quantificação hormonal em soro humano, como o EIE, a quimiluminescência e a espectrometria de massas (RODINI, 2008). A espectrometria de massas já foi 
utilizada para dosar progesterona em saliva humana (LEITH; TRURAN; GASKELL, 1986).

As enzimas são os marcadores mais utilizados na atualidade, com as vantagens de não apresentarem riscos associados à exposição de radioisótopos. O EIE apresenta ainda outras vantagens sobre o RIE: maior sensibilidade; menos trabalho e economia de tempo; uso mais econômico do anticorpo e utilização de equipamentos de menor custo (RODINI, 2008).

A utilização de matriz biológica alternativa, como a saliva, possibilita o estudo da endocrinologia reprodutiva em animais nos quais o estudo pela matriz biológica sanguínea é impossibilitado, devido a fatores como tamanho e comportamento do animal (GUIMARÃES, 2003).

O perfil hormonal de progesterona salivar obtido neste estudo mostrou aumento significativo na concentração deste hormônio em D5, porém não foi sustentado, voltando a apresentar aumento significativo a partir de D9. Os resultados nas concentrações salivares de progesterona apresentaram aumento significativo dois dias após os obtidos nas concentrações séricas e uma inconsistência em relação ao parâmetro sérico, fato este que contraria o esperado. A inconsistência encontrada nas concentrações salivares de progesterona em relação ao parâmetro sérico pode ter ocorrido devido à pequena amostra estuda e às variações individuais.

Camargos et al. (1988) avaliaram a concentração de progesterona em amostras salivares colhidas diariamente de mulheres durante todo o ciclo menstrual e encontraram que o perfil de progesterona na saliva refletiu o classicamente encontrado em sangue. Camargos (1989), porém, ao investigar métodos não invasivos para monitorar a função ovariana cíclica da mulher, não obteve sucesso ao tentar usar o primeiro aumento significante na concentração salivar de progesterona como método para predizer ovulação. Este aumento, no entanto, marcou o final do período fértil em mais de $80 \%$ das pacientes.

Os resultados obtidos neste trabalho se assemelham aos encontrados por Camargos (1989), pois, embora não tenhamos conseguido usar o primeiro aumento significante na concentração salivar de progesterona para predizer a ovulação, podemos usar esse dado para predizer que o período fértil da cadela se encerrou.

Já foi relatado que a dosagem sérica de progesterona para estimar o momento ótimo para cruzamento em cadelas é confiável por RIE com ${ }^{125}$ I e que 
técnicas utilizando kits de ELISA são bastante imprecisas (VAN KLAVEREN et al., 2001).

Embora haja dados na literatura que demonstram não haver influência do fluxo salivar nas concentrações de esteróides salivares em humanos e nem da higiene dental na estabilidade deste hormônio (VINING, MCGINLEY; SYMONS, 1983; BOEVER et al., 1990; PIRES, 2008), não há estas informações para cães. No presente estudo não foi medida a taxa de fluxo salivar e nem tampouco realizada exames para avaliar higiene e saúde buco-dental dos animais.

Quando se realiza dosagem de esteróides em amostras urinárias, os valores individuais de creatinina são utilizados na correção dos valores obtidos para impedir que as variações de volume possam influir nos valores de hormônios mensurados, pois a creatinina não sofre alteração mesmo que os volumes urinários sejam diferentes (FURTADO, 2007). Não há nenhum parâmetro semelhante para corrigir variações no volume salivar. 
CONCLUSÃO 


\section{CONCLUSÃO}

Nas condições em que o experimento foi conduzido, podemos concluir que:

- O conjunto diagnóstico comercial Immunotech ${ }^{\circledR}$ (Beckman Coulter Company, Marseille, France) foi validado laboratorialmente para quantificação de progesterona sérica em cadelas por RIE.

- É possível obter volume suficiente de saliva para quantificação de progesterona em cadelas com o uso do dispositivo Salivette ${ }^{\circledR}$.

- Observou-se correlação positiva e forte entre as concentrações sérica e salivar de progesterona em cadelas.

- O conjunto diagnóstico comercial Salimetrics ${ }^{\circledR}$ (State College, PA, USA) foi validado biologicamente para quantificação de progesterona salivar em cadelas por EIE.

- Não é possível utilizar a dosagem de progesterona na saliva para predizer a ovulação, mas é possível utilizá-la para avaliar o fim do período fértil de cadelas. 


\section{REFERÊNCIAS}




\section{REFERÊNCIAS}

ALLEN, W. E. Fertilidade e Obstetrícia no Cão. São Paulo: Varela, 1995. 197p.

ALVES, I.; MATEUS, M.; LOPES DA COSTA, L. Monitorização do ciclo éstrico da cadela para inseminação artificial ou cruzamento. In: CONGRESSO DE CIÊNCIAS VETERINÁRIAS, 1., 2002, Lisboa. Proceedings of the veterinary sciences congress. Lisboa: Sociedade Portuguesa de Ciências Veterinárias, 2002, p. 177-182.

AMARAL, R. S. Uso de diferentes matrizes biológicas na dosagem de andrógenos em peixes-bois da Amazônia machos (Trichechus inunguis) mantidos em cativeiro. 2008. 85 f. Dissertação (Mestrado em Medicina Veterinária) - Faculdade de Medicina Veterinária e Zootecnia, Universidade de São Paulo, São Paulo, 2008.

BEACH, F. A.; DUNBER, I. F.; BUEHLER, M. G. Sexual characteristics of female dogs during successive phases of the ovarian cycle. Hormones and Behavior, $v$. 16, n. 4, p. 414-442, 1982.

BENETTI, A. H.; TONIOLLO, G. H.; OLIVEIRA, J. A. Concentrações séricas de progesterona, 17ß-estradiol e cortisol durante o final do proéstro, estro e diestro gestacional em cadelas. Ciência Rural, v. 34, n. 2, p. 471-478, 2004.

BOEVER, J. D.; KOHEN, F.; BOUVE, J.; LEYSEELE D.; VANDEKERCKHOVE, D. Direct chemiluminescence immunoassay of estradiol in saliva. Clinical Chemistry, v. 36, n. 12, p. 2036-2041, 1990.

CALAMARI, C. V. Avaliação das concentrações de testosterona no pêlo de cães domésticos (Canis lupus familiaris). 2008. $92 \mathrm{f}$. Tese (Doutorado em Medicina Veterinária) - Faculdade de Medicina Veterinária e Zootecnia, Universidade de São Paulo, São Paulo, 2008.

CAMARGOS, A. F.; DONALDSON, A.; SUFI, S. B.; JEFFCOATE, A. L. Qual o valor dos constituintes da saliva para predizer ovulação? Reprodução, v. 3, n. 1, p. 25-28, 1988. 
CAMARGOS, A. F. Investigação de métodos não invasivos para monitorar a função ovariana na mulher. Reprodução, v. 4, p. 25-34, 1989.

CARREIRA, R. P.; COLAÇO, A. A.; SILVA, J. R. Avaliação da estabilidade da progesterona em diferentes tipos de amostras: soro e leite desnatado. Revista Portuguesa de Ciências Veterinárias, v. 98, n. 548, p. 207-209, 2003.

CONCANNON, P. W. Effects of hypophysectomy and of LH administration on luteal phase plasma progesterone levels in the beagle bitch. Journal of reproduction and fertility, v. 58, p. 407-410, 1980.

CONCANNON, P. W.; HANSEL, W.; MCENTEE, K. Changes in LH, progesterone and sexual behavior associated with preovulatory luteinization in the bitch. Biology of Reproduction, v. 17, n. 4, p. 604-613, 1977.

CONCANNON, P. W.; HANSEL, W.; VISEK, W. J. The ovarian cycle of the bitch: plasma estrogen, LH and progesterone. Biology of Reproduction, v.13, n. 1, p. 112-121, 1975.

CONCANNON, P. W.; McCANN, J. P.; TEMPLE, M. Biology and endocrinology of ovulation, pregnancy and parturition in the dog. Journal of reproduction and fertility, v. 39, p. 3-25, 1989. Supplement.

CONCANNON, P. W.; WEIGAND, N.; WILSON, S.; HANSEL, W. Sexual behavior in ovariectomized bitches in response to estrogen and progesterone treatments.

Biology of Reproduction, v. 20, n. 4, p. 799-809, 1979.

DAVIDSON, A. P.; STABENFELDT, G. H. Controle da ovulação e do corpo lúteo. In: CUNNINGHAM, J. G. Tratado de Fisiologia Veterinária. 2. ed., Rio de Janeiro: Guanabara Koogan, 1999. p. 361-367.

DERUSSI, A. A. P.; LOPES, M. D. Fisiologia da ovulação, da fertilização e do desenvolvimento embrionário inicial na cadela. Revista Brasileira de Reprodução Animal, v. 33, n. 4, p. 231-237, 2009.

DRESCHEL, N. A.; GRANGER, D. A. Methods of collection for salivary cortisol measurement in dogs. Hormones and Behavior, v. 51, n. 1, p. 163-168, 2009. 
ENGLAND, G. C.; ALLEN, W. E.; PORTER, D. J. A comparison of radioimmunoassay with quantitative and qualitative enzyme-linked immunoassay for plasma progestogen detections in bitches. Veterinary Records, v. 125, n. 5, p. 107108, 1989.

FANTBONNE, A. Infertility in bitches and queens: recent advances. Revista Brasileira de Reprodução Animal, v. 35, n. 2, p. 202-209, 2011.

FREITAS, J. G.; SILVA, A. R. Diagnóstico de gestação em cadelas. Revista Brasileira de Reprodução Animal, v. 32, n.1, p. 58-66, 2008.

FURTADO, P. V. Perfil analítico de estrógenos e progestinas em diferentes matrizes biológicas na espécie ovina (Ovis Aires). 2007. 96 f. Tese (Doutorado em Medicina Veterinária) - Faculdade de Medicina Veterinária e Zootecnia, Universidade de São Paulo. São Paulo, 2007.

GAO, Y.; SHORT, R. V.; FLETCHER, T. P. Progesterone concentrations in plasma, saliva and milk of cows in different reproductive states. British Veterinary Journal, v. 144 , n. 3, p. 262-268, 1988.

GOODMAN, M. Ovulation timing. Concepts and controversies. Veterinary Clinics of North America: Small Animal Practice, v. 31, n. 2, p. 219-235, 2001.

GOODROWE, K. L.; WALKER, S. L.; RYCKMAN, D. P.; MASTROMONACO, G. F.; HAY, M. A.; BATERMAN, H. L.; WADDELL, W. T. Piecing together the puzzle of carnivore reproduction. Animal Reproduction Science, v. 2, n. 60-61, p. 389-403, 2000.

GRÖSCHL, M.; RAUH, M.; DÖRR, H. Circadian rhythm of salivary cortisol, 17ahydroxyprogesterone, and progesterone in healthy children. Clinical Chemistry, v. 49, n. 10, p. 1688-1691, 2003.

GRÖSCHL. M.; RAUH, M. Influence of commercial collection devices for saliva on the reliability of salivary steroids analysis. Steroids, v. 71, n. 13-14, p. 1097-1100, 2006.

GUIMARÃES, M. A. B. V. The importance of the application of non-invasive techniques in the study of wild animal reproduction. Annual Review of Biomedical Sciences, v. 5, n. 1, p. 29-37, 2003. 
HAECKEL, R.; HÄNECKE, P. The application of saliva, sweat and tear fluid for diagnostic purposes. Annales de Biologie Clinique, v. 51, n.10-11, p. 903-910, 1993.

HAFEZ, E. S. E. Hormônios, fatores de crescimento e reprodução. In: Reprodução Animal. 6. ed. São Paulo: Manole, p.59-94, 1995.

HOFFMANN, B.; RIESENBECK, A.; KLEIN, R. Reproductive endocrinology of bitches. Animal Reproduction Science, v. 42, n. 1, p. 275-288, 1996.

HOFMAN, L. F. Human saliva as a diagnostic specimen. Journal of Nutrition, v. 131, n. 5, p. 1621-1625, 2001.

ISHIKAWA, M.; SENGOKU, K.; TAMATE, K.; TAKAOKA, Y.; KANE, M.; FOTTRELL, $P$. F. The clinical usefulness of salivary progesterone measurement for the evaluation of the corpus luteum function. Gynecologic and Obstetric Investigation, v. 53, n. 1, p. 32-37, 2002.

JÖCHLE, W.; ANDERSEN, A. C. The estrous cycle in the dog: a review. Theriogenology, v. 7, n. 3, p. 113-140, 1977.

JOHNSTON, S. D.; KUKUSTRITZ, M. V. R.; OLSON, P. N. S. Canine and feline reproduction. Philadelphia: Saunders Company, 2001.592 p.

KIESS, W.; PFAEFFLE, R. Análise de esteróides na saliva: uma ferramenta nãoinvasiva para pesquisa em pediatria e clínica médica. Jornal de Pediatria, v. 83, n. 3, p. 97-99, 2007.

KISO, Y. YAMAUCHI, S. Histochemical study on hydroxysteroid dehydrogenases in the trophoblast of the dog placenta. Japanese Journal of Veterinary Science, $v$. 46, n. 2, p. 219-223, 1984.

KOWALEWSKI, M. P.; BECERIKLISOY, H. B.; ASLAN, S.; AGAOGLU, A. R.; HOFFMAN, B. Time related changes in luteal prostaglandin synthesis and steroidogenic capacity during pregnancy, normal and antiprogestin induced luteolysis in the bitch. Animal Reproduction Science, v. 116, p. 129-138, 2009.

LEITH, H. M.; TRURAN, P. L.; GASKELL, S. J. Quantification of progesterone in human saliva. Biological Mass Spectrometry, v. 13, n. 5, p. 257-261, 1986 
LEWIS, J. G. Steroid analysis in saliva: an overview. The Clinical Biochemist Reviews, v. 27; p. 139-146, 2006.

LUZ, M. R. Manejo del apareamiento em la especie canina. In: GOBELLO, C. (Org.). Temas de reproducción de caninos y felinos por autores latino-americanos. La Plata: Intermédica, 2004. p. 99-106.

MANDEL, I. D. The diagnostic uses of saliva. Journal of Oral Pathology \& Medicine, v. 19, n. 3, p. 119-125, 1990.

NORMAN, A. W.; LITWACK, G. Steroid hormones: chemistry, biosynthesis, and metabolism. In: Hormones. 2nd ed. San Diego: Academic Press, 1997. 558 p.

OKKENS, A. C.; DIELEMAN, S. J.; BEVERS, M. M.; LUBBERINK, A. A. M. E.; WILLEMSE, A. H. Influence of hypophysectomy on the lifespan of the corpus luteum in the cyclic dog. Journals of Reproduction and Fertility, v. 77, n. 1, p. 187-192, 1986.

OLIVEIRA, E. C. S.; MARQUES JR., A. P. Endocrinologia reprodutiva e controle da fertilidade da cadela. Revista Brasileira de Reprodução Animal, v. 30, n. 1/2, p. 11-18, 2006.

O’RORK, A.; KANE, M. M.; GOSLING, J. P.; TALLON, D. F.; FOTTRELL, P. F. Development and Validation of a Monoclonal Antibody Enzyme Immunoassay for Measuring Progesterone in Saliva. Clinical Chemistry, v. 40, n. 3, p. 454-458, 1994.

PALME, R. Measuring fecal steroids - guidelines for practical application. Annals of the New York Academy of Sciences, v. 1046, p. 75-80, 2005.

PFAFFE, T.; COOPER-WHITE, J.; BEYERLEIN, P.; KOSTNER, K.; PUNYADEERA, C. Diagnostic potential of saliva: current state and future applications. Clinical Chemistry, v. 57, n. 5, p. 675-687, 2011.

PIRES, A. L. Estudo do perfil salivar e sérico em gestantes e não-gestantes. 2008. 87 f. Dissertação (Mestrado em Ciências da Saúde) - Universidade de Brasília, Brasília, 2008. 
PIETRASZEK, J.; ATKINSON, S. Concentrations of estrone sulfate and progesterone in plasma and saliva, vaginal cytology, and bioelectric impedance during the estrous cycle of the Hawaiian monk seal (Monachus schauinslandi). Marine Mammal Science, v. 10, n. 4, p. 430-441, 1994.

RODINI, D. C. Perfil analítico das progestinas fecais nas fases de puberdade e ciclicidade ovariana em Onça Pintada (Panthera onca); gestação e lactação em Gato Mourisco (Puma yagouaroundi). 2008. $74 \mathrm{f}$. Tese (Doutorado em Medicina Veterinária) - Faculdade de Medicina Veterinária e Zootecnia, Universidade de São Paulo, São Paulo, 2008.

ROTA, A.; VERONESI, M. C.; VOLPE, S.; RICCARDI, A.; BATTOCCHIO, M. Estradiol-17ß, progesterone and testosterone plasma concentrations during estrus in the bitch. Veterinary Research Communications, v. 31, n.1, p. 197-199, 2007.

SCHAEFERS-OKKENS, A. C. Ciclo Estral e Manejo Reprodutivo da Cadela Sadia. In: ETTINGER, S. J.; FELDMAN, E. C. Tratado de medicina interna veterinária: Doenças do Cão e do Gato. 4. ed.vRio de Janeiro: Guanabara Koogan, 2004. v. 2, p. 1592-1602.

SHIRTCLIFF, E. A.; GRANGER, D. A.; SCHWARTZ, E.; CURRAN, M. J. Use of salivary biomarkers in biobehavioral research: cotton-based sample collection methods can interfere with salivary immunoassay results.

Psychoneuroendocrinology, v. 26, p. 165-173, 2001.

SILVA, L. D. M.; SILVA, A. R.; CARDOSO, R. C. S. Inseminação artificial em cães. In: GONÇALVES, P. B. D.; FIGUEIREDO, J. R.; FREITAS, V. J. F. Biotécnicas Aplicadas à Reprodução Animal. São Paulo: Varela, 2001. p. 69-95.

SILVA, M. R. C. Comparação das concentrações de progesterona sérica e progestinas fecais em cadelas. 2005. 90 f. Dissertação (Mestrado em Medicina Veterinária) - Faculdade de Medicina Veterinária e Zootecnia, Universidade de São Paulo, São Paulo, 2005.

SRIKANDAKUMAR, A.; INGRAHAM, R. H.; ELLSWORTH, M.; ARCHBALD., L. F.; LIAO A.; GODKE, R. A. Comparison of a solid-phase, no-extraction radioimmunoassay for progesterone with an extraction assay for monitoring luteal function in the mare, bitch, and cow. Theriogenology, v. 26, n. 6, p. 779-793, 1986.

SUGIMOTO, M.; WONG, D. T.; HIRAYAMA, A.; SOGA, T; TOMITA, M. Capillary electrophoresis mass spectrometry-based saliva metabolomics identified oral, breast and pancreatic cancer-specific profiles. Metabolomics, v. 6, p. 78-95, 2010. 
THOREL, J. I.; LARSON, S. M. Radioimmunoassay and related techniques. Saint Louis: Mosby Company, 1978. 289 p.

VAN KLAVEREN, N. J.; KOOISTRA, H. D.; DIELEMAN, S. J.; VAN LITH, H. A.; SCHAEFERS-OKKENS, A. C. The optimal mating time in the bitch based on the progesterone concentration in peripheral blood. A comparison of reliability between three ELISA test kits and a 125-iodine radioimmunoassay. Tijdschrift voor diergeneeskunde, v. 126, n. 1, p. 680-585, 2001.

VERVERIDIS, H. N.; BOSCOS, C.; STEFANAKIS, A.; KRAMBOVITIS, E. Use of enzyme-immunoassay for oestradiol $-17 \beta$ and progesterone quantification in canine serum. Animal Reproduction Science, v. 69, n. 1-2, p. 53-64, 2002.

VINCENT, I. C.; MICHELL, A. R. Comparison of cortisol concentration in saliva and plasma of dogs. Research in Veterinary Science, v. 53, n. 3, p. 342-345, 1992.

VINING, R. F.; MCGINLEY, R. A.; SYMONS, R. G. Hormones in Saliva: Mode of Entry and Consequent Implications for Clinical Interpretation. Clinical Chemistry, v. 29, n. 10, p. 1752-1756, 1983.

WILDT, D. E.; PANKO, W. B.; CHAKRABORTY, P. K.; SEAGER, S. W. J.

Relationship of serum estrone, estradiol-17 $\beta$ and progesterone to $\mathrm{LH}$, sexual behavior and time of ovulation in the bitch. Biology of Reproduction, v. 20, n. 3, p. 648-658, 1979. 


\section{APÊNDICE A - Resultados das concentrações séricas e salivares de progesterona dos animais $\mathrm{C} 1, \mathrm{C2}, \mathrm{C3}, \mathrm{C} 4, \mathrm{C} 5, \mathrm{C} 8, \mathrm{C}$, C10 e C12}

As tabelas e gráficos a seguir apresentam os resultados das concentrações séricas e salivares de progesterona das cadelas C1, C2, C3, C4, C5, C8, C9, C10 e C12 individualmente.

Tabela 4 - Resultado das concentrações séricas e salivares de progesterona de C1

\begin{tabular}{ccc}
\hline & \multicolumn{2}{c}{$\mathrm{C1}$} \\
\hline D-9 & progesterona sérica $(\mathrm{ng} / \mathrm{mL})$ & progesterona salivar $(\mathrm{pg} / \mathrm{mL})$ \\
D-7 & 0,55 & 83,73 \\
D-4 & 1,00 & 404,02 \\
D-1 & 2,35 & 341,68 \\
D2 & 2,69 & 404,05 \\
D4 & 25,77 & 584,63 \\
D7 & 30,45 & 656,79 \\
D12 & 24,82 & 461,69 \\
\hline
\end{tabular}

Gráfico 6 - Representação gráfica das concentrações séricas e salivares de progesterona em C1

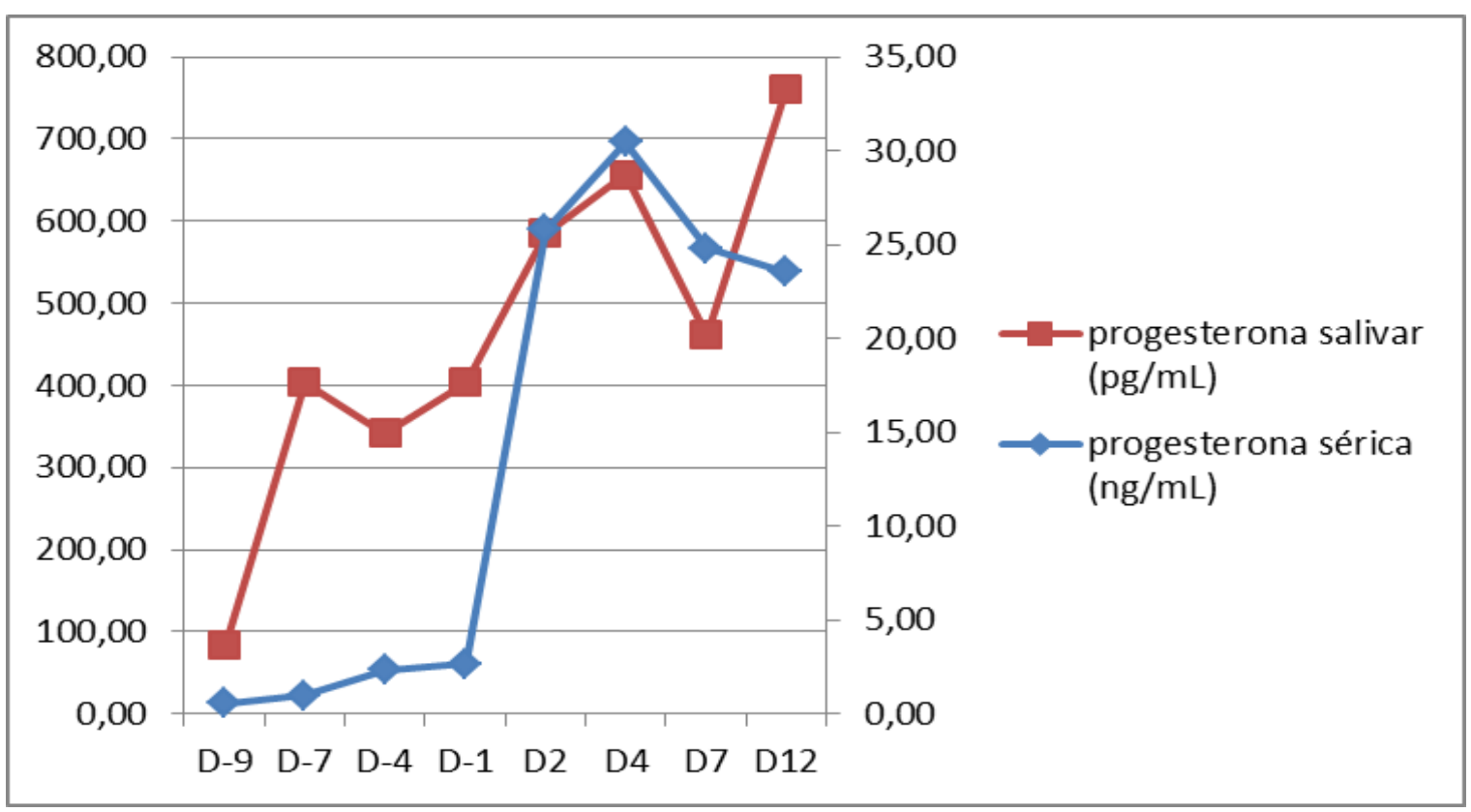


Tabela 5 - Resultado das concentrações séricas e salivares de progesterona de C2

C2

\begin{tabular}{ccc}
\hline & progesterona sérica $(\mathrm{ng} / \mathrm{mL})$ & progesterona salivar $(\mathrm{pg} / \mathrm{mL})$ \\
\hline D-6 & 0,61 & 251,54 \\
D-3 & 0,50 & 49,42 \\
D2 & 7,03 & 156,69 \\
\hline
\end{tabular}

Gráfico 7 - Representação gráfica das concentrações séricas e salivares de progesterona em C2

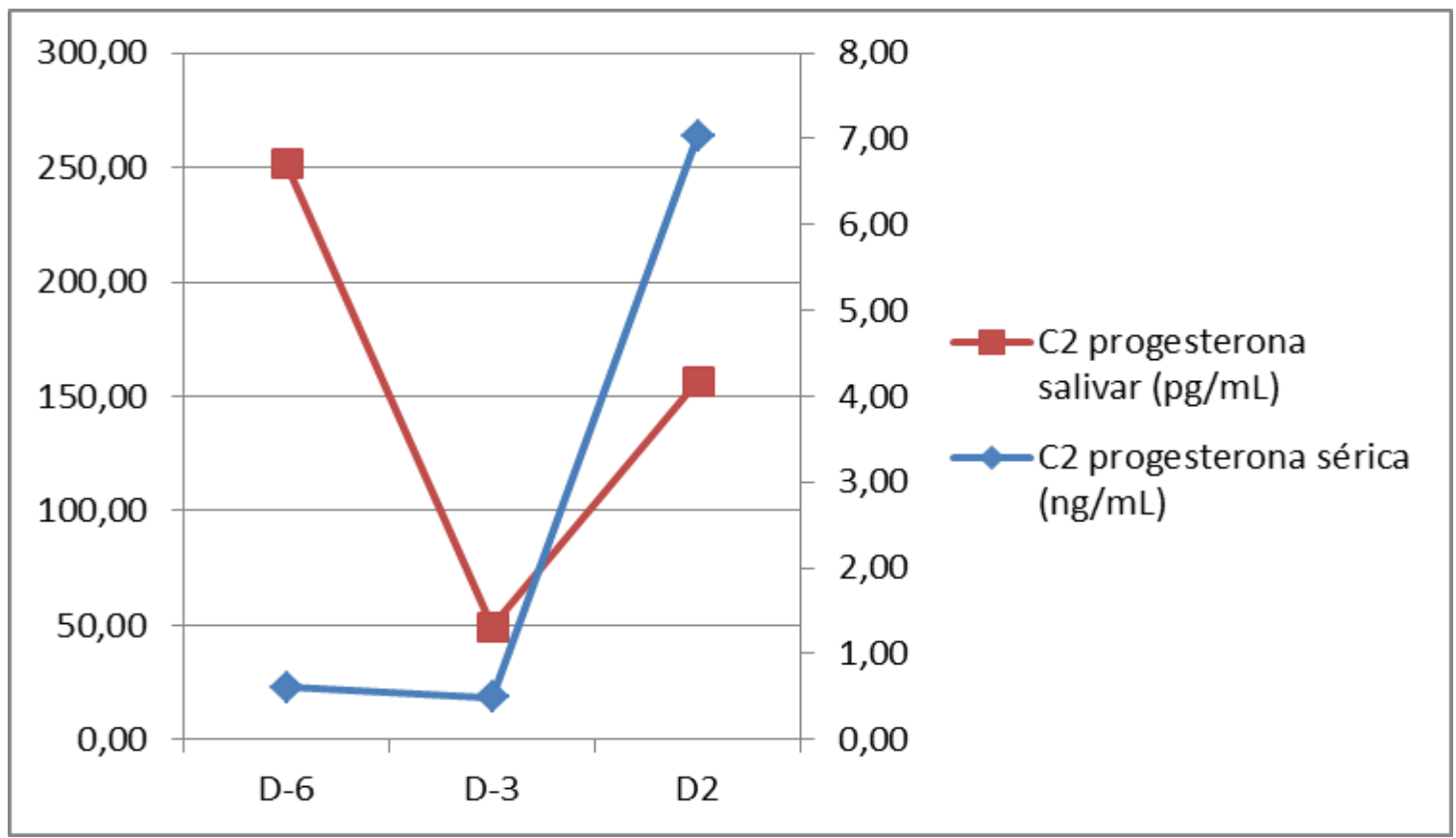


Tabela 6 - Resultado das concentrações séricas e salivares de progesterona de C3 (momento periovulatório a)

\begin{tabular}{ccc}
\hline \multicolumn{2}{c}{ C3 (momento a) } \\
\hline D0 & progesterona sérica $(\mathrm{ng} / \mathrm{mL})$ & progesterona salivar $(\mathrm{pg} / \mathrm{mL})$ \\
D2 & 4,70 & 111,63 \\
D5 & 12,77 & 521,57 \\
D9 & 26,89 & $1.709,23$ \\
D14 & 31,85 & $1.040,81$ \\
& 39,50 & $2.292,42$ \\
\hline
\end{tabular}

Gráfico 8 - Representação gráfica das concentrações séricas e salivares de progesterona em C3 (momento peri-ovulatório a)

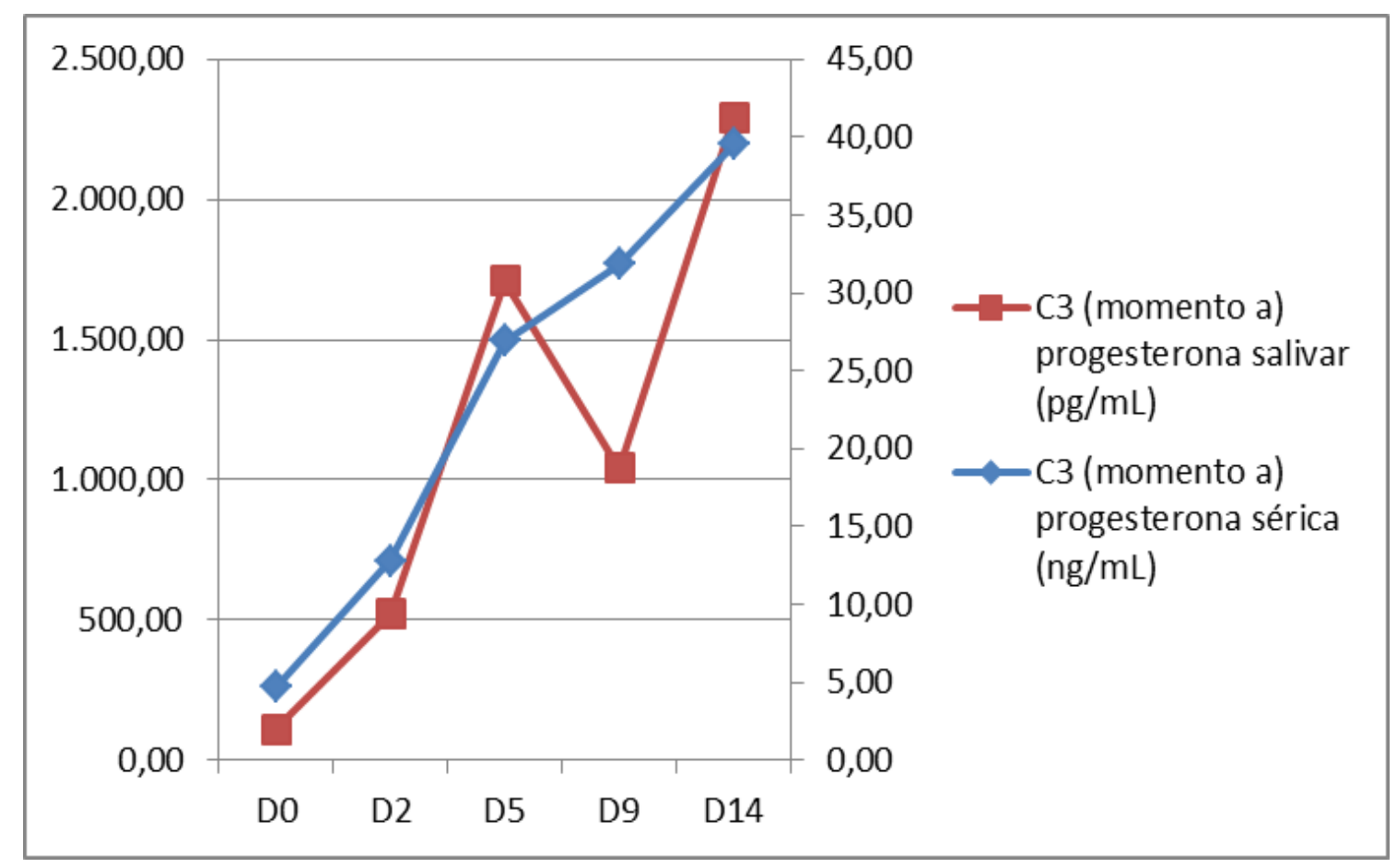


Tabela 7 - Resultado das concentrações séricas e salivares de progesterona de C3 (momento periovulatório b)

\begin{tabular}{ccc}
\hline \multicolumn{2}{c}{ C3 (momento b) } \\
\hline D-3 & progesterona sérica $(\mathrm{ng} / \mathrm{mL})$ & progesterona salivar $(\mathrm{pg} / \mathrm{mL})$ \\
D-2 & 1,06 & 96,19 \\
D0 & 1,88 & 174,46 \\
D3 & 4,07 & 67,09 \\
D5 & 13,57 & 410,76 \\
D10 & 21,94 & 492,02 \\
\hline
\end{tabular}

Gráfico 9 - Representação gráfica das concentrações séricas e salivares de progesterona em C3 (momento peri-ovulatório b)

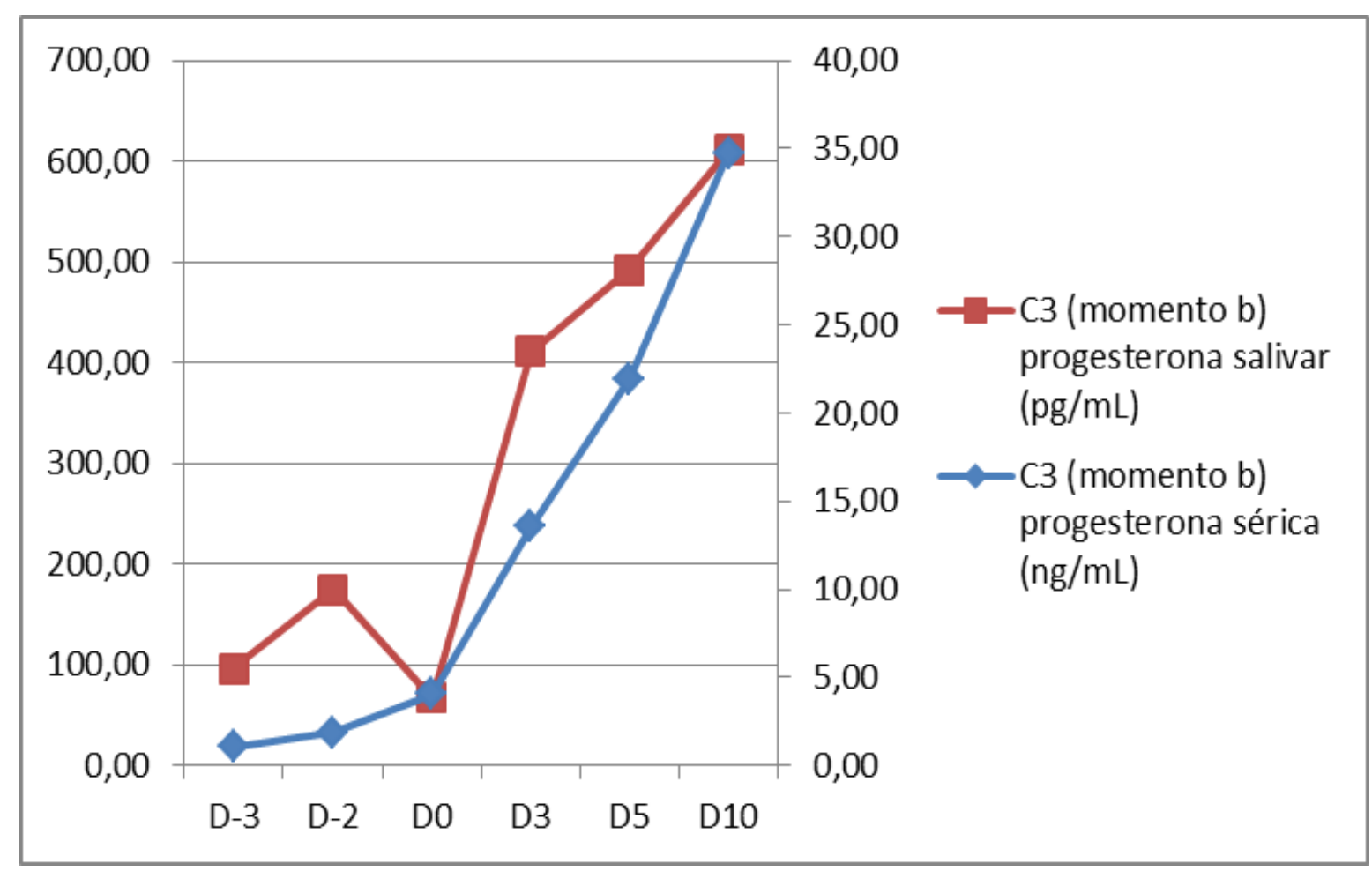


Tabela 8 - Resultado das concentrações séricas e salivares de progesterona de C4

\begin{tabular}{ccc}
\hline & \multicolumn{2}{c}{ C4 } \\
\hline D-6 & progesterona sérica $(\mathrm{ng} / \mathrm{mL})$ & progesterona salivar $(\mathrm{pg} / \mathrm{mL})$ \\
D0 & 2,94 & 77,04 \\
D2 & 4,92 & 184,62 \\
D5 & 5,41 & 173,46 \\
D7 & 18,85 & 479,61 \\
\hline
\end{tabular}

Gráfico 10 - Representação gráfica das concentrações séricas e salivares de progesterona em C4

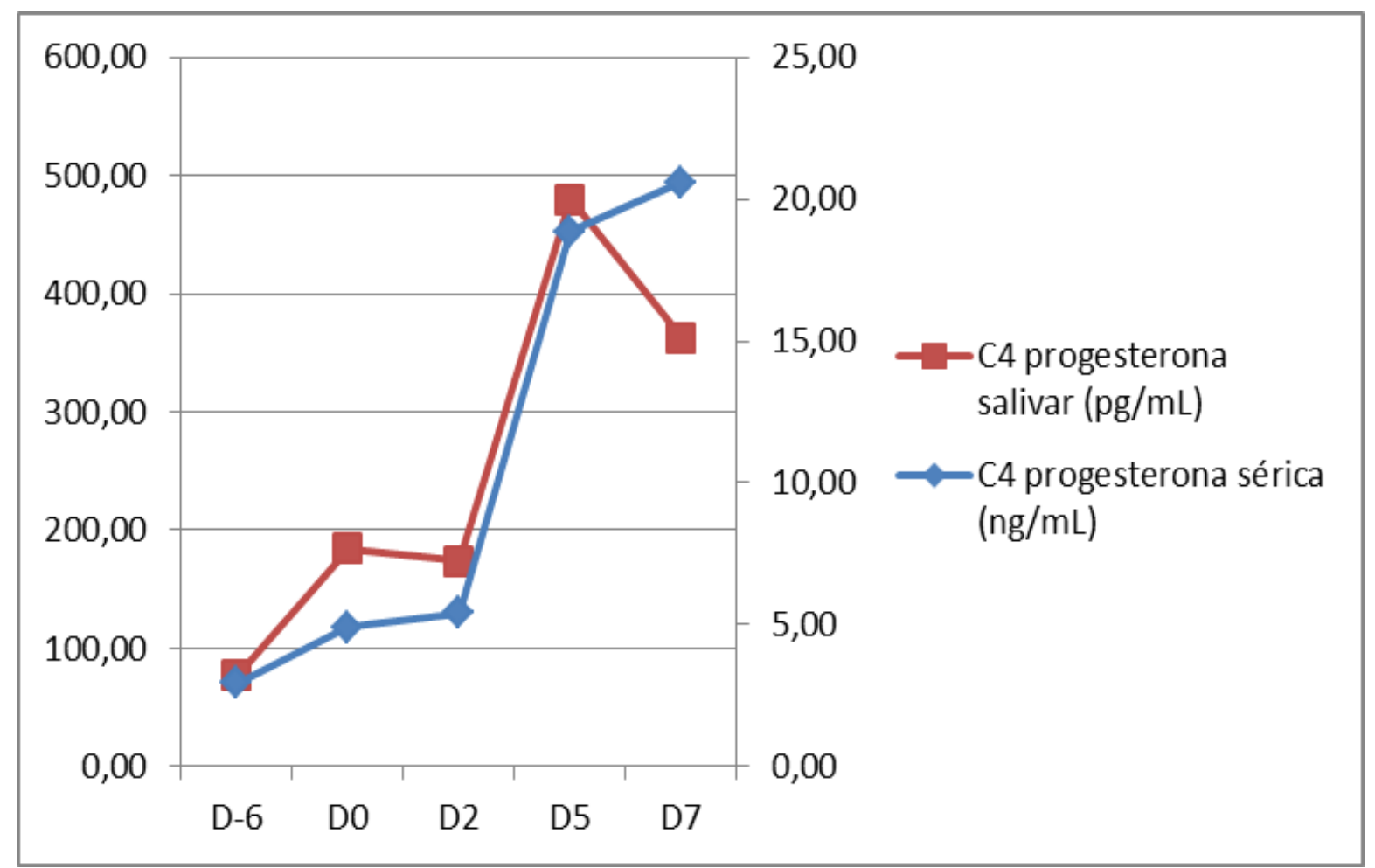


Tabela 9 - Resultado das concentrações séricas e salivares de progesterona de C5

\begin{tabular}{ccc}
\hline & \multicolumn{2}{c}{ C5 } \\
\hline D-3 & progesterona sérica $(\mathrm{ng} / \mathrm{mL})$ & progesterona salivar $(\mathrm{pg} / \mathrm{mL})$ \\
D1 & 1,83 & 64,54 \\
D6 & 10,39 & 143,31 \\
\end{tabular}

Gráfico 11 - Representação gráfica das concentrações séricas e salivares de progesterona em C5

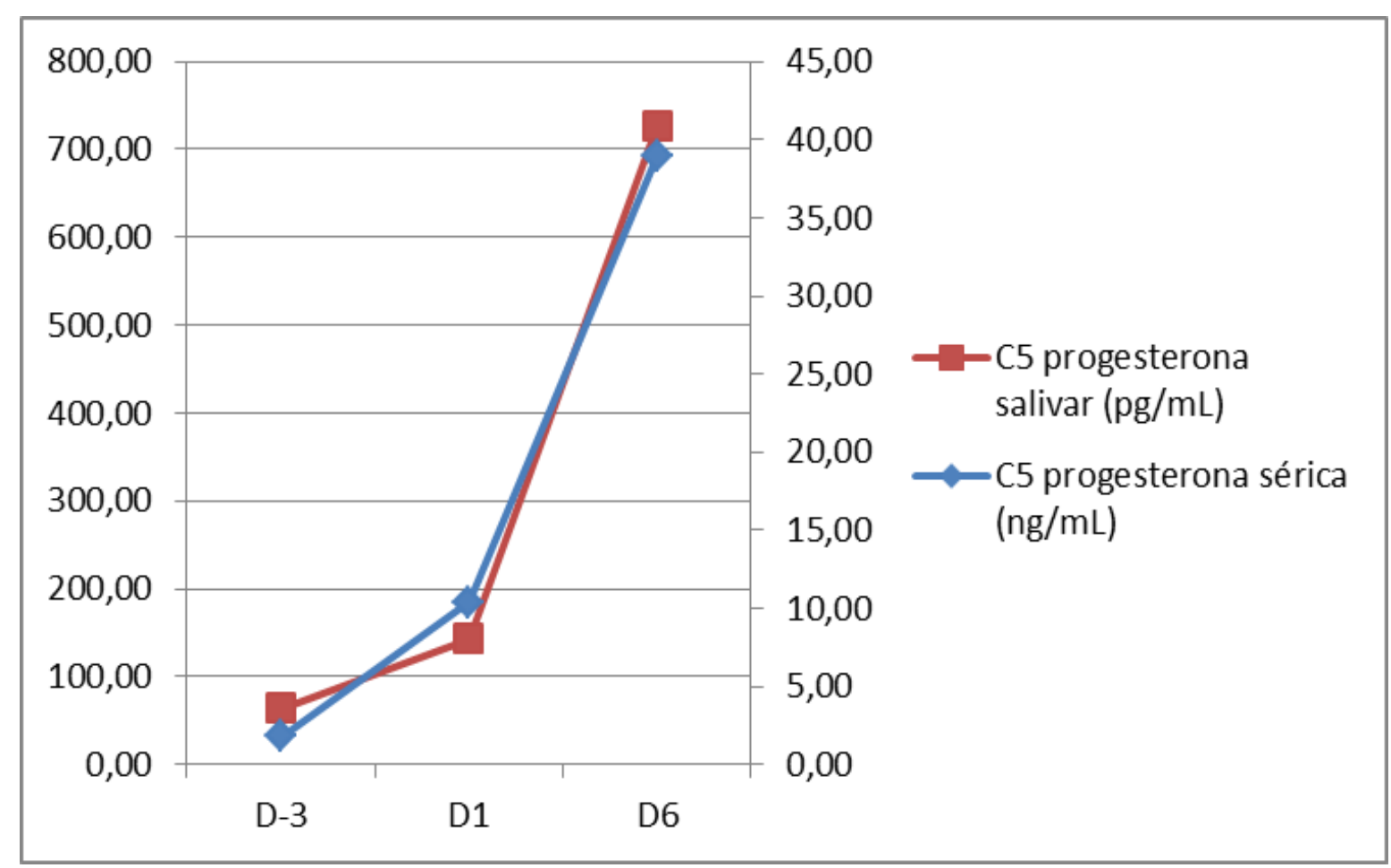


Tabela 10 - Resultado das concentrações séricas e salivares de progesterona de C8

\begin{tabular}{ccc}
\hline \multicolumn{2}{c}{ C8 } \\
\hline D0 & progesterona sérica $(\mathrm{ng} / \mathrm{mL})$ & progesterona salivar $(\mathrm{pg} / \mathrm{mL})$ \\
D1 & 5,14 & 178,59 \\
D2 & 8,77 & 78,68 \\
D3 & 12,30 & 145,14 \\
D4 & 19,57 & 221,04 \\
D5 & 29,32 & 322,86 \\
D6 & 26,89 & 368,76 \\
D7 & 30,75 & 625,04 \\
D8 & 27,31 & 427,88 \\
D9 & 34,69 & 656,79 \\
D10 & 30,09 & 566,82 \\
D11 & 29,73 & 836,69 \\
D12 & 33,52 & 940,76 \\
\hline
\end{tabular}

Gráfico 12 - Representação gráfica das concentrações séricas e salivares de progesterona em C8

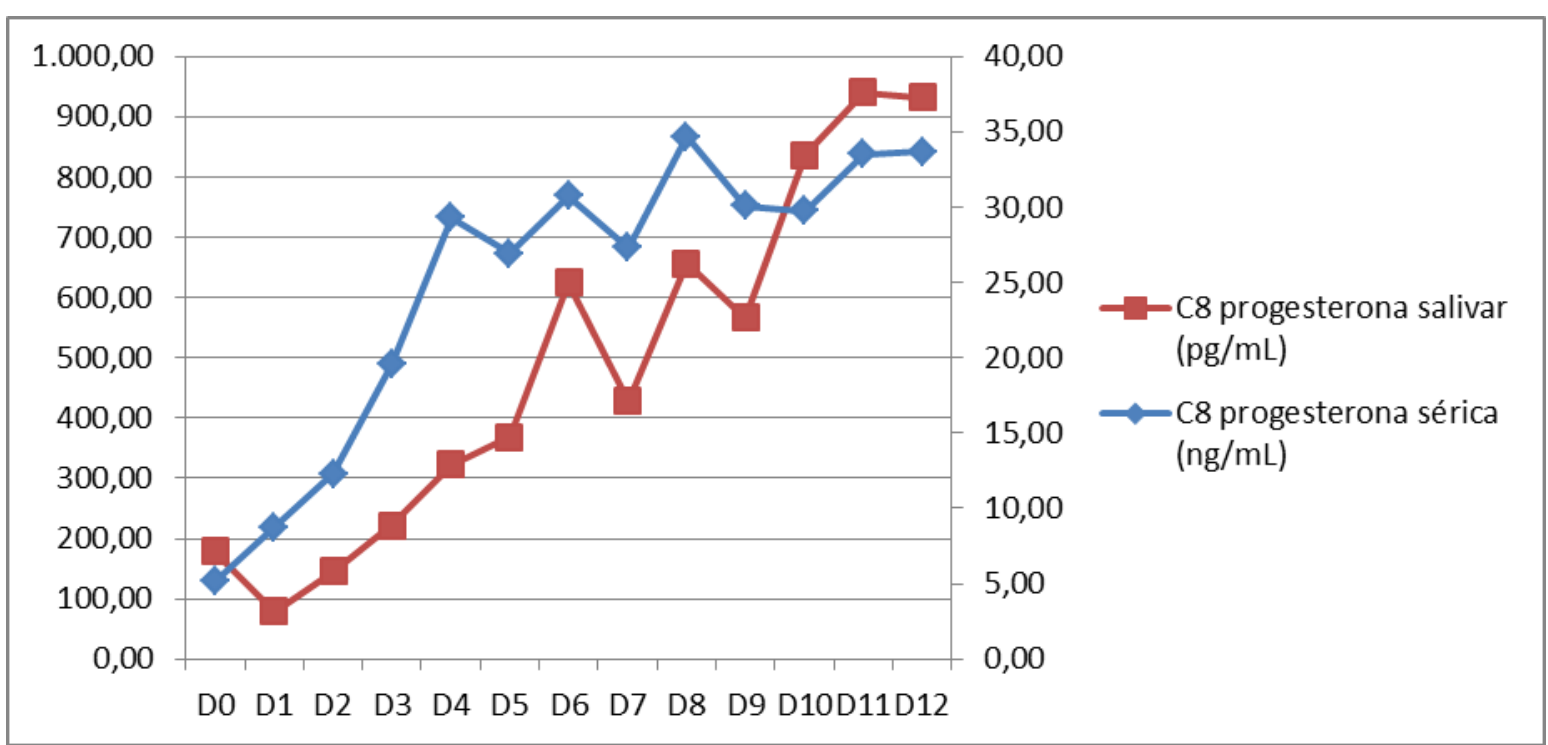


Tabela 11 - Resultado das concentrações séricas e salivares de progesterona de C9

\begin{tabular}{ccc}
\hline \multicolumn{2}{c}{ C9 } \\
\hline D0 & progesterona sérica $(\mathrm{ng} / \mathrm{mL})$ & progesterona salivar $(\mathrm{pg} / \mathrm{mL})$ \\
D2 & 4,45 & 85,97 \\
D4 & 11,17 & 76,90 \\
D6 & 12,74 & 180,08 \\
D8 & 20,44 & 172,69 \\
\hline
\end{tabular}

Gráfico 13 - Representação gráfica das concentrações séricas e salivares de progesterona em C1

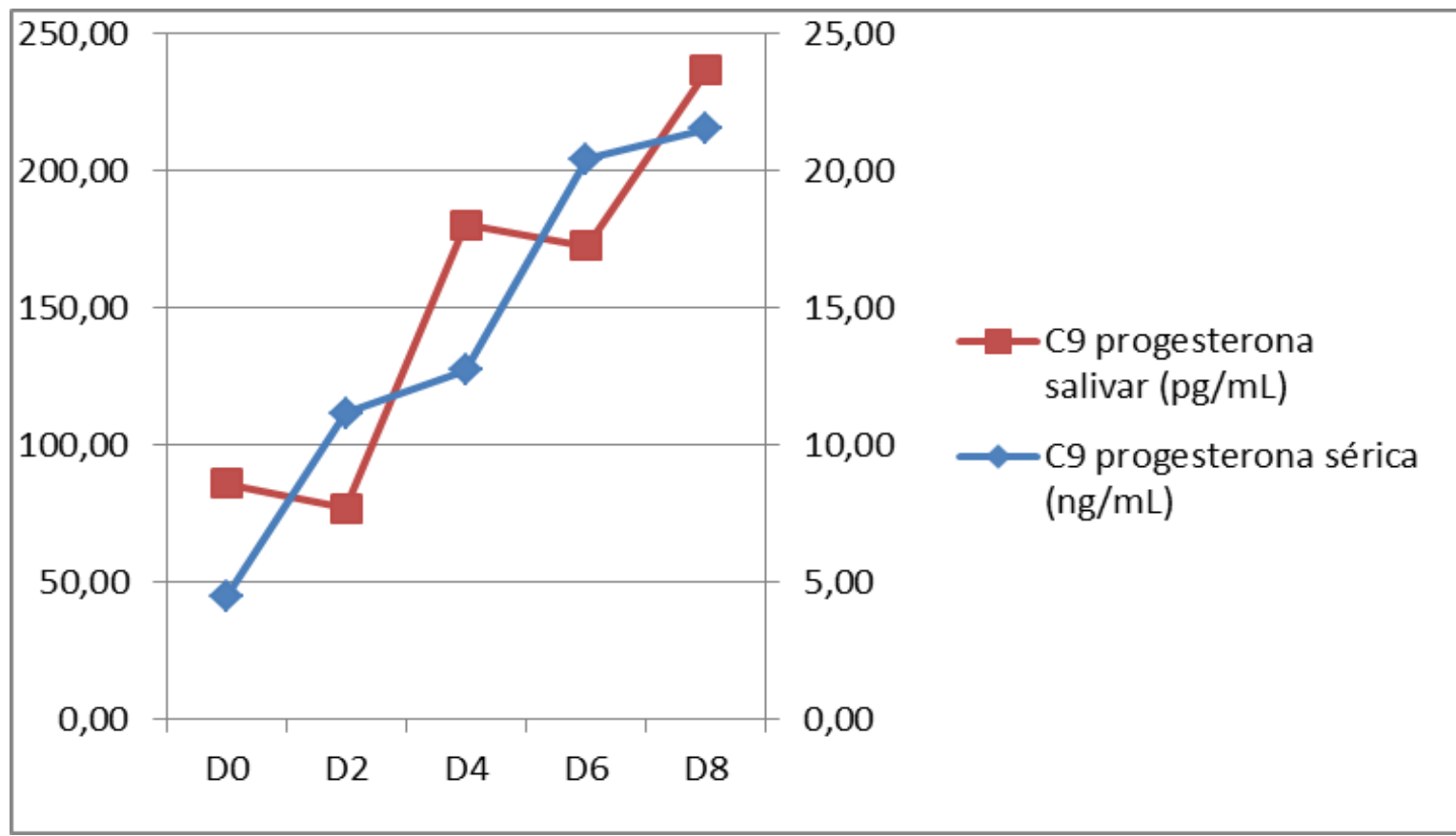


Tabela 12 - Resultado das concentrações séricas e salivares de progesterona de C10 (momentoperi-ovulatório a)

C10 (momento a)

\begin{tabular}{ccc}
\hline & progesterona sérica $(\mathrm{ng} / \mathrm{mL})$ & progesterona salivar $(\mathrm{pg} / \mathrm{mL})$ \\
\hline D-1 & 3,19 & 130,68 \\
D1 & 5,94 & 146,66 \\
\hline
\end{tabular}

Gráfico 14 - Representação gráfica das concentrações séricas e salivares de progesterona em C10 (momento-peri-ovulatório a)

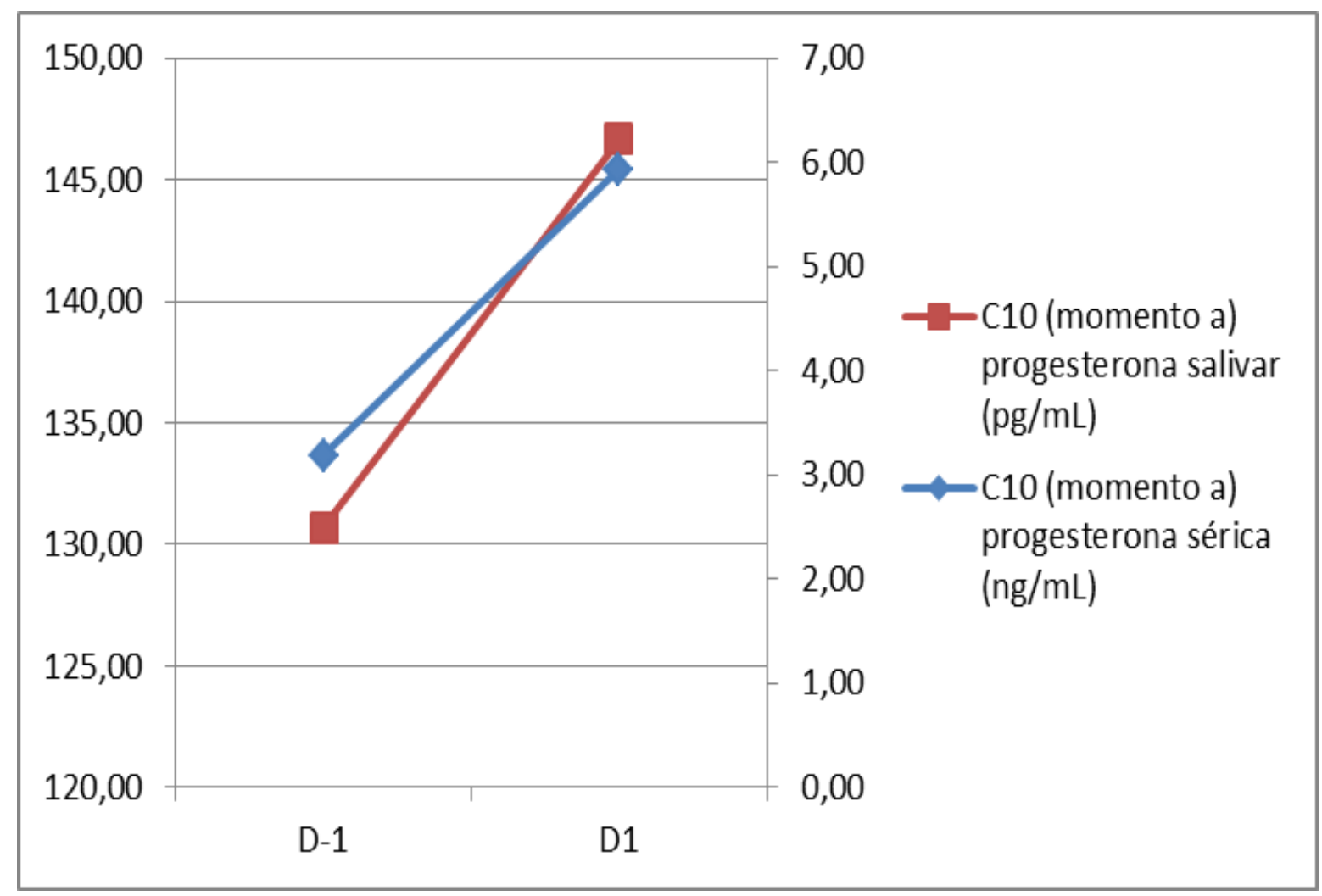


Tabela 13 - Resultado das concentrações séricas e salivares de progesterona de C10 (momentoperi-ovulatório b)

\section{$\mathrm{C} 10$ (momento b)}

progesterona sérica $(\mathrm{ng} / \mathrm{mL})$

progesterona salivar $(\mathrm{pg} / \mathrm{mL})$

\begin{tabular}{ccc}
\hline D-2 & 2,43 & 444,65 \\
D1 & 5,49 & 569,33 \\
\hline
\end{tabular}

Gráfico 15 - Representação gráfica das concentrações séricas e salivares de progesterona em C10 (momento-peri-ovulatório b)

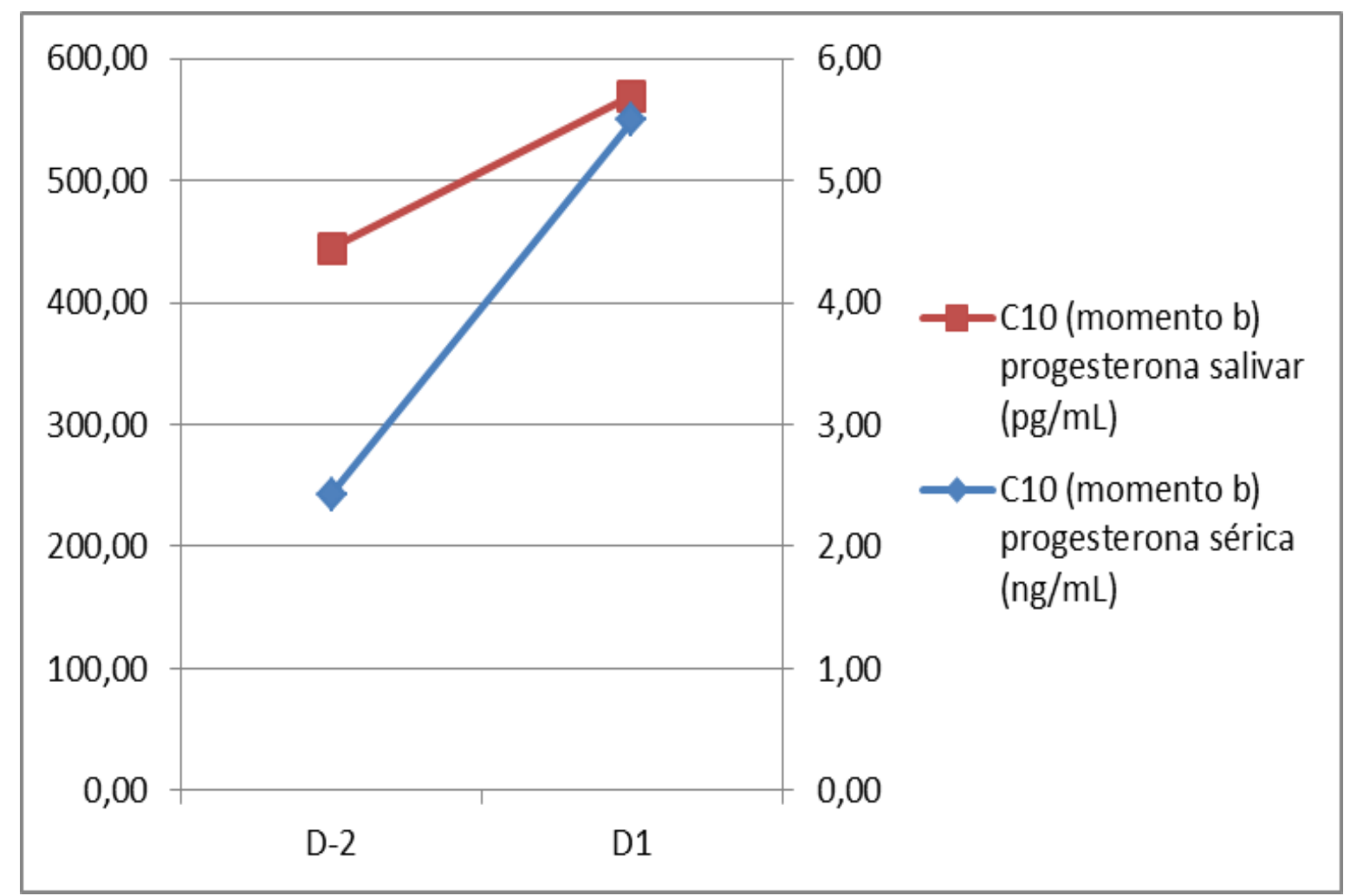


Tabela 14 - Resultado das concentrações séricas e salivares de progesterona de C12

C12

\begin{tabular}{ccc}
\hline & progesterona sérica $(\mathrm{ng} / \mathrm{mL})$ & progesterona salivar $(\mathrm{pg} / \mathrm{mL})$ \\
\hline D-3 & 1,28 & 224,00 \\
D-1 & 1,89 & 185,71 \\
D2 & 17,77 & 141,83 \\
D3 & 28,76 & 156,25 \\
\hline
\end{tabular}

Gráfico 16 - Representação gráfica das concentrações séricas e salivares de progesterona em C12

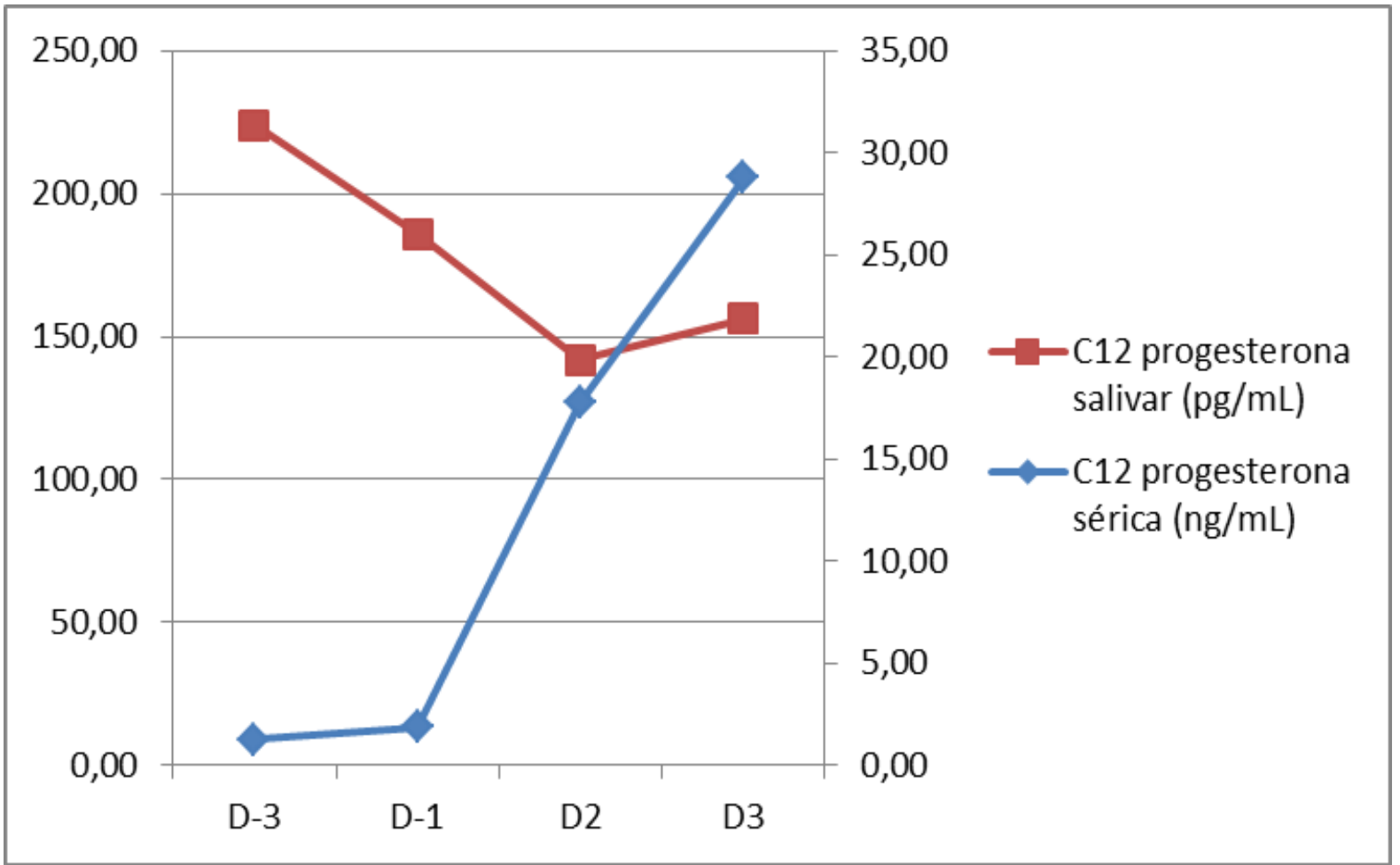

